\title{
Proeses que les barceloneses dones han ostentat en este siti de l'any 1706: una aproximació filològica
}

\author{
Proeses que les barceloneses dones han ostentat en este siti de l'any \\ 1706: a philological aproach
}

\author{
Marc Sogues Marco \\ marcsogues@gmail.com \\ Universitat de Girona
}

\begin{abstract}
Resum: Durant el setge borbònic de Barcelona de l'any 1706, es produí una contraofensiva dels barcelonins per recuperar la fortalesa de Montjuïc en la qual les dones de la ciutat tingueren un paper molt destacat. Aquesta participació va ser lloada en una relació en vers que va circular a través un plec solt intitulat Proeses que les barceloneses dones ban ostentat en este siti de l'any 1706. L'obra és coneguda dins l'àmbit de la historiografia, però fins ara no disposàvem de cap acostament al text que proporcionés al lector una edició filològicament fiable, actualitzada i comentada del poema complet, de manera que aquest és l'objectiu del present treball. Per assolir-lo, l'article s'estructura en tres parts: 1) l'enquadrament del text dins el seu context històric i cultural; 2) la seva descripció i interpretació a la llum de les eines metodològiques i conceptuals de la teoria literària i de la comparatística; i 3) l'establiment del text a partir de l'acarament crític de tots els testimonis disponibles i la seva edició, amb l'adaptació ortogràfica i els aparats crítics corresponents.
\end{abstract}

Paraules clau: Poesia catalana, literatura barroca, dones, setge de Barcelona, Guerra de Successió Espanyola

\begin{abstract}
During the Bourbon siege of 1706, the inhabitants of Barcelona launched a counter-offensive in order to recover the fortress of Montjuic. The women of the city played a significant role in this actions and their participation was praised in an account of events written in verse that circulated through a libel entitled Proeses que les barceloneses dones han ostentat en este siti de l'any 1706 (Feats that Barcelona women bave shoum in this site of the year 1706). This work is well known in the field of historiography, but nonetheless, until this moment, no approach has been proposed providing the reader with a philologically reliable, updated and commented edition of the complete poem. Therefore this is the objective of the present work. To achieve this objective, the article is structured in three parts: 1) the framing of the text in its historical and cultural context; 2) its description and interpretation in the light of the methodological and conceptual tools of literary theory and comparative literature; and 3) the establishment of the text based on the critical comparison of all the available printed testimonials and its edition, with the spelling adaptation and the corresponding critical apparatus..
\end{abstract}

Keywords: Catalan poetry, baroque literature, women, siege of Barcelona, War of the Spanish Succession 


\section{Introducció*}

A la primeria del mes d'abril de 1706, en el marc de la contraofensiva per recuperar el control del Principat de Catalunya, un exèrcit francocastellà comandat pel pretendent francès Felip d'Anjou va posar setge a Barcelona. A desgrat de la inferioritat numèrica, la ciutat, controlada pels austriacistes, va resistir durant un mes, fins que l'arribada d'una esquadra anglesa va capgirar la proporció de forces i va provocar l'aixecament del setge i la retirada precipitada dels assetjants.

En el relat austriacista d'aquests esdeveniments hi ha un episodi que crida vivament l'atenció per la seva aparent excepcionalitat: el que descriu la participació activa de les dones en la defensa de la ciutat durant els combats que tingueren lloc a Montjuïc el dia 22 d'abril. Aquest episodi, que consta en la major part de les fonts històriques conservades, va ser també objecte d'una relació en vers, publicada anònimament en forma de plec solt amb el títol de Proeses que les barceloneses dones han ostentat en este siti de l'any 1706.

El de les Proeses... és un text ja conegut en l'àmbit acadèmic i que ha estat divulgat també entre el gran públic. ${ }^{1}$ La major part dels treballs precedents tenen una orientació eminentment historiogràfica i s'hi aproximen des d'una perspectiva de gènere, assenyalant la importància de la informació que el text ens proporciona sobre el paper de la dona en la Barcelona de principis del segle XVIII. Ara bé: cap d'aquests estudis dedica a l'obra una atenció monogràfica i, malgrat que tots en recullen citacions, cap en reprodueix el text sencer, i Vall (2015: 153) és l’únic que el presenta amb les grafies regularitzades (vv. 97-104 i vv. 205-214).

Tenint en compte aquests antecedents, m'ha semblat oportú de proposar un acostament distint al text, que posés l'atenció en la seva dimensió literària i que proporcionés al lector una edició filològicament fiable, actualitzada i comentada del poema complet, de manera que aquest és l'objectiu del present treball. Per assolir-lo, aquest article s'estructura en tres parts, corresponents a les perspectives des de les quals, a parer meu, s'ha de plantejar qualsevol aproximació filològica rigorosa: 1) l'enquadrament del text dins el seu context històric i cultural; 2) la seva descripció i interpretació a la llum de les eines metodològiques i conceptuals de la teoria literària i de la comparatística; i 3) l'establiment del text a partir de l'acarament crític de tots els testimonis disponibles i la seva edició, amb l'adaptació ortogràfica i els aparats crítics que correspongui. Després d'examinar l'obra des d'aquests angles, recopilaré en un apartat final els principals resultats obtinguts, en base als quals formularé algunes reflexions a mode de conclusió, just abans de presentar la meva proposta d'edició.

\footnotetext{
* Aquest treball s'inscriu en el projecte de recerca del Ministerio de Economía y Competitividad, ref. FFI2015-70095-P. Vull fer constar el meu agraïment a Albert Rossich, Eulàlia Miralles i Pep Valsalobre, per les valuoses remarques que m'han fet sobre l'estudi i a l'edició del text. A Xavier Vall he d'agrair-li les orientacions relatives a la poesia i el teatre català de l'època de la Guerra de Successió espanyola i a Verònica Zaragoza, les relatives al rol de la dona en la societat catalana de les primeries del XVIII. Cristina Fontcuberta m'ha ajudat amb les reflexions sobre les connotacions identitàries de la representació de santa Eulàlia, santa Madrona i sant Jordi en època moderna. I Xevi Camprubí m’ha fet diverses recomanacions bibliogràfiques i algunes valoracions de conjunt relatives al món de la impremta i la circulació d'impresos a la Catalunya de l'època, totes de la màxima utilitat. Per últim, la historiadora i arxivera Mercè Gras m'ha proporcionat les referències a les cròniques de Parets i Giribets; les hi vull agrair totes dues, però especialment la de Giribets, atès que es tracta d'una obra que no ha tornat a ser reeditada des del segle XVIII i de la qual ella és, actualment, una de les poques coneixedores i, no obstant això, ha tingut l'amabilitat i la generositat de facilitar-me-la per a que pogués referir-m’hi en aquest treball. A totes i tots, doncs, el meu agraïment més sincer.

1 D’entre les de caire acadèmic, cal comptar les aportacions de Nash (2000: 22-25), Alabrús (2014: 182-183) i Vall (2015: 153-154). D’entre les divulgatives, destaquen Gabancho (2014: 113-114), Massanés / Serra (2014: 57) i Marimon (2013).
} 


\section{El context històric i cultural}

\subsection{El setge de Barcelona de 1706}

El 20 de juny de 1705, amb la signatura del Tractat de Gènova, el Principat de Catalunya abraçava la causa de l'arxiduc Carles dins el conflicte internacional de la Guerra de Successió Espanyola. Aquesta signatura propicià l'alçament dels vigatans i de bona part del rerepaís, que aplanà el camí per a la intervenció militar d'una aliança internacional conformada pel Sacre Imperi Germànic, la Gran Bretanya, les Províncies Unides, Portugal i els territoris de l'antiga Corona d'Aragó. Els exèrcits aliats posaren setge a Barcelona a finals d'agost del mateix any i el 9 d'octubre el virrei Velasco capitulava, obligat per la desigualtat de forces amb els assetjadors i per l'aixecament dels barcelonins en contra d'ell i dels Borbons. L'arxiduc entrà al Cap i Casal el 22 del mateix mes i fou proclamat rei el 7 de novembre, després d'haver jurat les Constitucions catalanes.

La reacció filipista no es féu esperar: la contraofensiva de l'exèrcit de les dues corones, integrat per tropes castellanes i franceses i comandat personalment pel pretendent francès retornà efímerament al Borbó el control d'una part del Principat i li permeté de plantejar un nou setge sobre Barcelona, que quedà formalment establert el 3 d'abril de 1706. La desproporció de les forces en conflicte era manifesta, ja que els assetjants disposaven de 18.500 soldats i d'un estol francès que assegurava el bloqueig marítim de la ciutat, mentre que els assetjats, comptant la cavalleria britànica, la infanteria austríaca i holandesa, els grups de voluntaris catalans i les milícies barcelonines, no depassaven els 8.500 efectius. $^{2}$ A més, tant les defenses de la ciutat com les de Montjuïc presentaven afectacions severes a causa dels setges suportats el 1697 i el 1705.

Durant el mes d'abril, l'esforç bèl lic dels atacants es dirigí cap a la presa de la fortalesa de Montjuïc, objectiu que aconseguiren la nit del dia 21. La matinada del 22, el migrat contingent de tropes aliades que resistia a la muntanya va iniciar la retirada amb el pretext de preservar per a la defensa de la ciutat les tropes i recursos que s'havien pogut salvar, però el poble de Barcelona interpretà aquesta acció com el preludi de la rendició de la plaça i pressionà el rei i les institucions catalanes per realitzar una contraofensiva. Aquest contraatac obtingué alguns resultats durant el matí del dia 22, però la posició de l'exèrcit atacant sobre el terreny era ja molt ferma, per la qual cosa la nit del 24 calgué donar definitivament per perduda la fortalesa.

Els darrers dies del mes d'abril i els primers del maig foren d'intensos bombardejos sobre la ciutat. Les tropes filipistes intentaren d'eixamplar les bretxes existents a les muralles i, a començaments de maig, s'arribà a considerar la possibilitat d'efectuar l'assalt a la ciutat a través d'aquestes obertures. L'opció però, fou descartada perquè les tropes aliades, amb l'incessant suport de la població civil, perseveraven diàriament a reforçar aquestes posicions. En l'entretant, el 8 de maig, una esquadra

2 Les dades dels efectius militars del setge provenen de Coroleu / Paredes (2014: 13). 
anglesa de cinquanta-sis naus $\mathrm{i}$ amb més de deu mil soldats de refresc recalava a Barcelona. ${ }^{3}$ En veure's clarament superada, la flota francesa es retirà, $i$ les tropes filipistes van quedar atrapades entre el foc de la ciutat i el de les partides de guerrillers que les hostilitzaven des de la rereguarda. Davant d'aquestes circumstàncies, el dia 11 de maig, el duc d'Anjou ordenà l'aixecament del setge i l'exèrcit de les dues corones emprengué una desordenada retirada fins a Perpinyà.

\subsection{Les Proeses... en el context de la literatura de guerra de la primeria del XVIII}

Tal com era de preveure, l'episodi de la resistència $\mathrm{i}$ desbaratament del setge va ser àmpliament explotat per la publicística austriacista. En dona fe Castellví, ${ }^{4}$ i n'ha quedat constància en la nodrida nòmina d'opuscles i plecs solts ${ }^{5}$ sobre l'afer que es conserven encara avui en diversos centres documentals del país. ${ }^{6}$

A la primeria del XVIII, al Principat, aquesta mena de publicacions de caràcter efímer i de rerefons bèl lic tenien ja una llarga i continuada tradició, que es remuntava als anys de la Guerra de Separació. ${ }^{7}$ Compostos i publicats majoritàriament a Barcelona, on a principis del Setcents es comptaven fins a dotze impremtes, ${ }^{8}$ solien tenir una difusió ràpida i capil lar per tots els racons del Principat, ${ }^{9}$ i contribuien a alimentar les «guerres de paper» que s'organitzaven en paral lel als enfrontaments armats i que influien decisivament en la presa de partit dels ciutadans per una o altra causa.

El text que aquí ens ocupa s'adscriu al gènere de les relacions de successos, un dels que més habitualment es transmetia per mitjà d'opuscles i plecs solts. ${ }^{10}$ Les relacions eren textos relativament breus, de caràcter popularitzant, que podien ser escrits en prosa o en vers i que servien per deixar constància de fets històrics més o menys rellevants, d’àmbit local o internacional. Malgrat la seva

3 La dada prové de Torras i Ribé (2007: 172).

4 El cronista reporta que, a començament del mes de juny de 1706, «Se esparcieron papeles, unos aludiendo al eclipse y retirada del ejército; otros, al triunfo del rey Carlos y aliados» (Mundet, J. / Alsina J.M. 1998: 120 [f. 97v]).

5 En tot el treball assumeixo les definicions proposades per Camprubí, d'acord amb les quals cal considerar opuscles les publicacions d'entre 12 i 100 pàgines i plecs solts els fulls de 12 pàgines o menys (2013: I, 86). El moment àlgid que travessa l'edició d'aquest tipus de publicacions a principis del XVIII és descrit pel mateix Camprubí, en el seu estudi del període 1642-1726: «L'increment de la producció de fulls de notícies es va produir també el 1706, coincidint amb el primer any de la campanya de l'exèrcit de l'arxiduc Carles d'Àustria a la península, cosa que fa augmentar la xifra total de plecs solts conservats d'aquell any fins a 106, la tercera més alta de tot el període estudiat» (2013: I, 91).

6 Cal destacar, en aquest sentit, la col lecció d'impresos que conforma el Fons Bonsoms de la Biblioteca de Catalunya.

7 Sobre la literatura de guerra d'aquest període, vegeu Ettinghausen (2014: 163-164) i Miralles (2010, 2011, 2012).

8 Camprubí (2013: I, 57).

9 Per copsar la rapidesa amb què podia arribar a circular la informació pel Principat a principis del segle XVIII, vegeu Camprubí (2014).

10 Sobre el sorgiment del gènere de les relacions a Catalunya, vegeu Ettinghausen (2014: 151-153).

SCRIPTA, Revista internacional de literatura i cultura medieval i moderna, núm. 10/desembre 2017/pp. 191-228 ISSN: 2340 - 4841 doi:10.7203/SCRIPTA.10.11077 
pretensió de veracitat, el gènere transitava pels llindars -sempre difusos, en aquesta època- que separaven la protopremsa, la crònica històrica de la literatura de creació. Això vol dir que, a més a més d'emprar recursos retòrics i estratègies discursives propis de la literatura de creació, en les relacions el rigor històric sovint se supeditava als propòsits literaris i ideològics del text. Construien, així, visions parcials i tendencioses dels fets relatats, per la qual cosa cal considerar que, a fi de comptes, la seva finalitat era sobretot política i propagandística.

Dins del panorama esbossat, l'obra objecte d'estudi presenta dues característiques importants. En primer lloc, està escrita en llengua catalana, quelcom que no té res d'extraordinari en aquesta època però que ens revela implícitament el públic al qual anava destinada. Més concretament, evidencia que, a diferència d'altres obres de característiques similars, el públic potencial de les quals podia arribar a ser d'àmbit hispànic (en el cas de les escrites en castellà) o fins i tot europeu (en el cas de les escrites en llatî), el de les Proeses... és un text pensat per al Principat i, sobretot, per ser difós a Barcelona.

\subsection{Dones, història i literatura en temps de setge}

El segon tret destacable de les Proeses... és que és l'única obra de què tenim constància que estigui dedicada específicament a la implicació de les dones durant el setge de 1706. Afinant encara una mica més, fins i tot podem dir que és l'única obra catalana de l'època moderna que té com a tema central l'actuació de les dones en una contesa bèl lica. Ara bé: com hem d'interpretar aquesta singularitat?

Podríem pensar que les dones no solien prendre part en els conflictes armats o bé que, si ho fèiem, no les fonts de l'època no n'acostumaven a deixar constància, però el cert és que, si examinem detingudament aquestes fonts, aviat ens adonarem que la implicació femenina en avalots, revoltes i fets bèl lics en època moderna a Catalunya no és un fet gens inusual i que està prou ben documentada. Per exemple, ja Miquel Parets feia constar de forma prou detallada com les dones van contribuir a la defensa de Barcelona durant l'atac de les tropes de Felip IV el gener de 1641, en l'intent de setge que s'acabaria resolent amb la batalla de Montjuïc. ${ }^{11}$ I el mateix es pot dir dels setges de 1705, 1706 i 1714, en els quals Castellví, Feliu i d'altres fonts testimonien la implicació femenina, tal com han remarcat aportacions de la bibliografia secundària recent com les de Nash (2000) o Alabrús (2014). No m’estenc més, de moment, sobre aquesta qüestió, perquè m’hi referiré més detingudament en el proper apartat, on compararé els fets recollits en aquestes fonts amb el relat construï a les Proeses....

11 «Però estant en ses cases y sentien los grans tirs de artilleria y mosqueteria, advertiren lo treball dels òmens y acudiren, al tems de la refrega, per les murallas, aportant provisions de bales, axí de mosquets y arcabús com de artilleria, y moltísimes de drapots per a taps de artilleria — que les muralles ne anaven plenas—, y vinagre y cals per a refrescar la artilleria; y en particular aportaven molt menjar y beura per la gent, abundant tant com ne volien, fins a confitures y altros regalos; que anaven per siutat ab senalles, aplegant: aquí los donaven un pa, altros los donave[n] vi, altros dinés y altres coses; y de aquexa manera, anaven per la muralla donant tant a menjar y beura a la gent com volían, y anant animant la gent ab molta alegria» (Margalef 2017: I, 17). 
Sí que voldria, però, fer una reflexió sobre la forma com són presentades les dones en el text de les Proeses.... En aquest sentit, tant per voler deixar constància del seu paper en un esdeveniment important, com pel seu to manifestament laudatori, ens pot semblar un text excepcional, però la realitat és que, si el situem dins el seu context històric, aquesta excepcionalitat ha de ser relativitzada. Sobretot, perquè la lloança de les dones, de fet, constitueix un topos amb una llarga tradició literària, que es remunta fins l'antiguitat clàssica i que floreix especialment a partir de la baixa edat mitjana com a revers de la literatura misògina. Té representants tan conspicus com Petrarca (De familiares) o Bocaccio (De claris mulieribus), o, a casa nostra, Bernat Metge (llibre IV de Lo sommi), Roís de Corella (Triumfo de les dones) o Joanot Martorell (capítol 309 del Tirant lo blanc), ${ }^{12}$ i té continuïtat arreu d'Europa durant tota l'època moderna, en la denominada querelle des femmes, el debat literari i acadèmic entorn de la capacitat intel lectual i els drets de les dones a l'accés al coneixement. ${ }^{13}$ Això sí: és important entendre que, sigui quina sigui l'atenció que es dedica a les dones en aquest tipus d'obres, podem parlar, si es vol, de filogínia, però en cap cas de feminisme, perquè aquest concepte no funciona fora d'un context contemporani i perquè en els textos antics les dones són lloades no pas per uns valors propis, sinó per aquell tipus d'actituds i capteniments que més les acosten als que, a l'època, es relacionaven amb els ideals de l'arquetipus masculí. ${ }^{14}$

En tot cas, i tot i que cal tenir presents aquests antecedents, el cert és que no existeix -que jo conegui- cap altra obra que, com les Proeses..., prengui una acció femenina com a matèria d'una relació de successos, si més no, en llengua catalana. I l'autor devia ser conscient de l'excentricitat del seu text, perquè, com explicaré en el següent apartat, sembla excusar-se fins a dues vegades pel tema escollit.

Tenint present tot això, em sembla que és oportú que ens demanem què podia moure un autor català de les primeries del XVIII a l'elaboració d'una obra de vocació comercial i popularitzant amb les dones com a protagonistes. Sóc del parer que, per respondre a aquesta pregunta, cal prendre en consideració factors de tipus polític i comercial. Deixo momentàniament de banda els primers, perquè m’hi referiré més endavant $i$, en relació amb els segons, cal recordar que ens trobem en una època en la qual els impressors tenien una de les seves principals fonts d'ingressos en la producció i comercialització de plecs solts i opuscles, el marge de benefici dels quals era força més gran

12 Sobre tots els casos esmentats aquí, i especialment sobre les obres en llengua catalana, vegeu Martín (2013).

13 Sobre la querrelle, vegeu Kelly (1982) i Frize (2013: 9-23).

14 «El debat antifemení té uns matisos i una sèrie de contrapunts en els elogis o en descripcions positives de les dones. Dins d'aquestes descripcions, els elogis d'heroïnes clàssiques conformen un tòpic i el que es destaca en elles són les virtuts masculines i la fidelitat. D'altra banda, les escasses vegades que trobem dones discretes i sàvies ens apareixen, d'una banda, embolcallades per escenes amoroses que desvirtuen una mica la imatge que en tenim, de l'altra amb uns coneixements de saviesa que no van més enllà de certes lectures molt concretes que representen una «vulgarització» del saber però que resulta interessant trobar-les en boca femenina. Hem d'arribar a Corella per veure un sentiment de filogínia que superarà la tradició medieval d'elogis femenins, escrits en defensa de les dones com a contrapunt al discurs misogin, $\mathrm{i}$ recuperarà la idea de la dona creada amb igualtat a l’home, gràcies a la perfecció del Creadon» (Martín 2013: 78). 
que no pas el dels llibres. ${ }^{15}$ En aquest context, el recurs a un tema inhabitual (i per tant, en certa manera, sorprenent), com era el cas de l'obra que ens ocupa, sens dubte devia de resultar un reclam per al lector de l'època, un ganxo que podia atraure la seva atenció i moure'l a adquirir-lo. A això cal afegir que l'episodi relatat era ben conegut (i celebrat) per les classes populars barcelonines, que havien instigat i participat en els fets del 22 d'abril, i cal suposar que devien trobar interès en veure'l representat en un text de les característiques de les Proeses..., la qual cosa significa que, quantitativament, el públic potencial de l’obra justificava sobradament la seva publicació.

\section{Anàlisi literària i proposta de lectura}

\subsection{Presentació del text}

Des del punt de vista formal, el poema és un romanç de 238 versos heptasíl labs, de rima assonant en o/o_ə en els versos parells. En línies generals, podem dir que és un text de bona factura, amb un discurs ben articulat i sense cap mancança des del punt de vista mètric ni fonètic. De fet, a nivell fonètic, fins i tot podem apreciar una rima interna («i del Rosselló, que foren / valeroses defensores / de sa pàtria i sa nació», vv. 221-223) i una al literació («esta finesa famosa», v. 192), recursos certament molt puntuals i purament ornamentals però que denoten una certa preocupació per part de l'autor per expressar-se en un estil que resulti plaent al lector. L'autor demostra en tot moment un bon domini de la sintaxi i una notable perícia versificatòria, que es concreta en un ús sovintejat de l'hipèrbaton, així com en els encavallaments, abundants i ben aconseguits.

La vocació popularitzant i divulgativa del text es fa palesa en el seu estil planer, unívoc i directe, desproveït de les metàfores i els jocs conceptuals habituals en la poesia barroca de caràcter culte. Prova d'aquesta vocació és també la utilització sovintejada del discurs directe («Germans!, volen de platillo o olla?», v. 157), fins i tot amb interpel lacions al lector/públic («haveu mai oït a dir...», v. 57), ${ }^{16}$ les comparacions de factura poc sofisticada (l'esforç de les dones les va fer suar tant com per omplir la cisterna de Montjuïc, vv. 143-145; els homes dins el castell s'amuntegaven «com a

15 «(...) durant el període estudiat [1642-1726], de cada 100 impresos que van sortir de les impremtes de Barcelona, 18 eren llibres, 25 eren opuscles i els restants 57 eren plecs solts. La proporció que mostra el fons conservat, malgrat que indica clarament la importància que les obres de petit format van tenir per a la impremta catalana, no és del tot real, ja que, sens dubte, la quantitat d'opuscles i de plecs solts fou molt superior a la que es conserva» (Camprubí 2013, I: 86). El mateix autor, en referir-se als avantatges que suposava la impressió d'obres breus sobre la de llibres, explica que «(...) la poca capacitat financera va obligar les impremtes a sobreviure basant-se en el curt termini, és a dir, a través de la impressió d'obres de poca extensió, que requerien una mínima inversió i que aportaven ingressos de forma gairebé immediata» (Camprubí 2016: 14).

16 Les relacions de successos, i especialment les que, com és el cas, eren escrites en vers, tot sovint, a part de ser llegides per un lector individual, estaven pensades (i escrites) per a ser llegides es veu alta. En aquest sentit, cal fer referència a la figura del «cec oracioner», un personatge molt popular a Catalunya, que es guanyava la vida recitant versos pels carrers, segons explica Camprubí (2013: I, 1104-1105). 
llagostes», v. 150), i l'ús d’una expressió de registre col loquial com és el cas de «Mamola!» (v. 200). Val a dir, així mateix, que és un text de caràcter netament laudatori, i que això es palesa sobretot en la seva caracterització en termes clarament hiperbòlics com «furioses lleones» (v. 66) i «sempre invictes matrones» (v. 216), entre d'altres.

És cert que el discurs transgredeix reiteradament la unitat de sentit semàntic que, en els romanços, acostumava a ajustar-se a la mesura de les quartetes, però aquesta llicència és excusable i comprensible en un text que no cercava el lluïment de l'autor, que devia ser compost amb una certa pressa i que, a més, era destinat a un suport de publicació de caràcter efímer i tenia com a principal objectiu transmetre un seguit d'idees de la forma més eficaç possible. Tanmateix, lluny de suposar cap perjudici per al bon desenrotllament del sentit de la narració, podem dir que l'esmentada llicència més aviat hi contribueix.

Podria sorprendre que, al costat de tots aquests aspectes, el text contingui també referències de naturalesa històricomitològica (Pirra i Semíramis, Bacus, la Fama, les dones de Tortosa i el Rosselló), imatges de llarga tradició literària (com la del cérvol ferit), i, fins i tot, al lusions al cànon literari català del moment (Vicent Garcia, Francesc Fontanella, Joan de Gualbes o Pau Miracle). ${ }^{17}$ Es tracta, però, d'elements que, més que no pas revelar una suposada voluntat cultista, el que fan es palesar fins a quin punt certs referents culturals eren àmpliament compartits per tots els estrats lectors, ja fossin els més cultes com els més populars.

Malgrat que és fàcil de copsar un cert component narratiu en el poema, i que, de fet, podríem aplicar-hi l'esquema de la introducció, nus i desenllaç, la meva impressió és que el propòsit que preval és el de persuadir, concretament, del mèrit de l'acció femenina. Per això em sembla que, més que no pas en clau narrativa, val la pena que ens hi aproximem com ho faríem amb un text argumentatiu. En aquest sentit, l'examen de la dispositio del poema -és a dir, de la seva estructura interna-, revela una organització de les idees pròpia dels principis elementals de la retòrica, de tal manera que és possible reconèixer-hi l'exordium (v. 1-18), on s'identifica el tema (la implicació de les dones en la defensa de la ciutat), se'n justifica l'elecció i es capta l'atenció del públic o del lector; la narratio (v. 19-56), on s'exposen els fets o circumstàncies que determinen les raons o causes que seran defensades posteriorment, i que, en aquest cas, són les del setge de Barcelona; l'argumentatio (v. 57-214), la part més extensa del text, on es basteix la tesi, el cor del discurs (la descripció i lloança de la implicació de les barcelonines), que s'apuntala amb gran profusió d'exemples; i, per acabar, la peroratio (v. 215-236), que reprèn i sintetitza la idea central amb la intenció de generar l'adhesió i la compartició de la mateixa per part del públic o el lector.

En un nivell més concret, dins aquest esquema general podem dir que el poema comença amb una introducció (v. 1-18) que serveix a l'anònim autor per centrar l'objectiu de la seva composició

$17 \mathrm{El}$ fet que aquests autors siguin esmentats aquí demostra que, si més no nominalment, eren àmpliament reconeguts -fins i tot, en els casos de Garcia i Fontanella, per estrats de la societat que segurament no els havien llegit mai- com a màximes autoritats poètiques en llengua catalana al Principat a l’inici del segle XVIII. 
i per realitzar la captatio preceptiva (v. 9-18). Es tracta, però, d'una captatio un tant particular perquè, tot i que, tal com és habitual en aquest tipus de passatges, l'autor comença referint-se a les seves pròpies limitacions com a literat (la seva «rústica trompa», v. 12), afegeix que aquestes limitacions li impedeixen de referir-se a qüestions més elevades, com ho serien el paper del rei i el dels generals en el setge (v. 9-10), i afirma, quasi a mode d'excusa, que és per aquest motiu que dedica els seus versos a les «proeses afanyoses / que en aquest siti han obrat / les barceloneses dones» (vv. 1416). Tot seguit, però, aquest menyspreament subtil queda en certa mesura contrapesat amb el reconeixement explícit que es tracta d'unes proeses «memorables» i que, com a tals, «no és just que el món les ignòria» (v. 18).

Dit això, s'explica que l'atac de l'exèrcit de les dues corones contra Montjuïc va agafar desprevinguda la defensa catalana (vv. 21-22) i que la fortalesa s'hauria perdut «en una hora» si no arriba a ser per la intercessió de les copatrones de la ciutat, santa Eulàlia i santa Madrona (vv. 25-26). Aquesta intercessió s'explica en termes vagues, per la qual cosa resulta una mica críptica (vv. 27-30), i, de fet, ben aviat es dona un motiu més terrenal per explicar per què no es va perdre del tot la fortalesa en aquell dia, i és que «sa Majestat» (l'arxiduc Carles) i «l'Excel lentíssima» (és a dir, el Consell de Cent), ordenaren la sortida de nous efectius per recuperar Montjuïc (vv. 35-40).

Aquí l'autor reitera la seva voluntat de no fixar-se en els protagonistes masculins de l'escena -els soldats de la Coronela i de la Guàrdia Reial Catalana- sinó únicament en les dones barcelonines, a les quals es refereix com a «matrones» (v. 52), apel latiu de prestigi i reverencialitat. Sorprenentment, però, i malgrat insistir en el mèrit de les proeses femenines, torna a justificar-se per l'elecció del tema. En aquest cas, ho fa apel lant a un argument ambigu («per saber só fill de dona», v. 54), però que probablement haguem d'interpretar en el sentit que, atès que tothom és fill de dona, qualsevol lector ha d'acceptar i aprovar aquesta elecció.

Fet això, comença l'enumeració de les accions heroiques dutes a terme per les barcelonines. S'afirma que porten pistoles, però no queda clar si les utilitzen o les proporcionen als soldats. El que sí que és clar és que no cerquen el resguard del castell, sinó que se situen al bell mig de la batalla (vv. 76-80). En aquest escenari, no només estimulen el valor dels combatents (v. 81), sinó que realitzen tasques d'infermeria, proporcionant benes i primers auxilis als ferits $\mathrm{i}$ col laborant en el seu trasllat a la ciutat (vv. 83-104). Animen els homes (vv. 105-108) i participen en el subministrament de "provisions de guerra i boca» (v. 112), que porten des de Barcelona. De fet, aquesta tasca -la d'avituallament dels combatents-, atreu l'atenció del cronista, que hi dedica el passatge més extens del text (vv. 109-191). L'interès sembla justificat per la «intrepidès» de l'acció, que obligà les dones bellugar-se entre les trinxeres i dessota el foc enemic, pel valor que exhibiren (ho feren tot «sens témer les borrascoses / ruixades de bales», vv. 140-141) i per la summa eficàcia i prodigalitat amb què la dugueren a terme. En aquest sentit, el text conta com les dones s'atansaven als soldats per proveir-los de peix, carn, pa, coques i vi, no fent distinció per rang - des de «los més pobres soldats» (v.155) «fins capitans d'estofa» (v. 174)- ni per nacionalitat 
(vv. 183-190). També remarca la seva «gran lliberalitat» (és a dir, la generositat), ja que refusen el pagament dels seus serveis perquè, segons diuen: «no ho fem per interès, / sinó per nostra honra pròpria; / per la pàtria i per lo rei, / per qui tot ho darem totes». El text també ens ennova dels efectes fatals que, per a algunes de les heroïnes, tingué la implicació en l'acció bèl lica (v. 201-208), si bé ens els presenta en termes èpics, referint-se a la mort d'algunes d'elles com un element que esperonava les companyes a perseverar en les seves tasques (vv. 205-214).

$\mathrm{Al}$ vers 214 es clou la narratio i es dona pas a la laudatio final, en la qual les barcelonines són equiparades a les llegendàries resistents del Setge de Tortosa, $\mathrm{i}$ amb les d'un altre acte heroic realitzat per congèneres rosselloneses que, per ara, no he pogut documentar (vv. 219-224). Tot plegat per culminar amb el que podia ser el màxim reconeixement públic concebible: el del monarca que, segons el text, va veure i celebrar la seva acció (vv. 225-236).

\subsection{Les Proeses... i les fonts històriques: un exercici comparatiu}

La participació femenina en els combats del dia 22 d'abril és un fet que hem de considerar positivament provat, perquè és reportat per la majoria de fonts de l'època que s'ocupen del setge de 1706 , ja siguin cròniques, dietaris oficials, protopremsa, relacions o obres de creació. ${ }^{18}$

Com ja he dit anteriorment, cal recordar que el text que ens ocupa es troba entre la crònica, el protoperiodisme i la literatura de creació, per la qual cosa no ens ha d'estranyar que, en alguns moments, sacrifiqui parcialment la fidelitat als esdeveniments en pro dels seus objectius literaris i ideològics. Essent així, tal com miraré d'evidenciar a continuació, un estudi comparatiu de les Proeses... amb les fonts coetànies de caràcter més netament historiogràfic pot resultar força productiu, perquè ens permetrà de constatar l'existència d'aquells punts on el relat del nostre plec divergeix, de forma més o menys anecdòtica segons el cas, del que construeixen les altres fonts, $\mathrm{i}$ extreure algunes conclusions sobre el significat d'aquestes divergències. Ara bé, com que realitzar una comparació exhaustiva i sistemàtica amb totes elles queda fora de l'abast d'aquest treball i a més a més resultaria molt feixuc per al lector, aquí em limitaré quasi exclusivament a comparar el relat construït a les Proeses... amb els de Castellví i Feliu, perquè les seves són dues de les cròniques més detallades de què disposem i perquè, en allò relatiu als aspectes als quals aquí em referiré, he pogut constatar que la resta de fonts no se n'allunyen substancialment.

18 Amb major o menor grau de detall, en trobem constància a les cròniques de Castellví (Mundet, J. / Alsina J.M. 1998, II: 93 [77v-78r]), Feliu (1999: III, 563) i Giribets (1707: 44). (Dec el coneixement d'aquesta última obra a la historiadora i arxivera Mercè Gras, a la qual, des d'aquí, vull manifestar el meu agraïment). També s'hi refereixen dos opuscles anònims que donen notícia en prosa dels fets del setge: la Diaria y verídica relación de las operaciones y sucesos del sitio de la Ciudad de Barcelona, desde el dia 31 de março de 1706 hasta la retirada del enemigo (F. Bon 554, p. 29) i Ecos de verdad en siete diálogos sobre lo sucedido en el asedio de Barcelona (F. Bon. 7543). Dins l’àmbit de la literatura de creació, l'episodi és referit dins l'obra llatina Barcelona assetjada pels francesos (Coroleu / Paredes 2014: 61) i dins la Comedia famosa del sitio de Barcelona y fuga del Duque de Anjou, de Josep Ribes (Foguet 2015: 81-82). 
Un primer aspecte de caire general que voldria assenyalar és que, ja des del títol, el text es focalitza en l'acció d'unes «barcelonines dones» que, al llarg de tot el poema romanen com un personatge col lectiu i anònim. Sembla, doncs, que a l'autor de les proeses no li interessa destacar cap dona en particular, sinó l'acció conjunta de totes elles. En canvi, a les cròniques, si bé les dones solen ser al ludides com a col lectiu la major part de les vegades, també hi podem trobar els casos de fins a tres figures femenines que se singularitzen per les seves accions i que són esmentades amb noms i cognoms: tant Castellví com Feliu fan constar el nom de Josefa Maria de Lila, que oferí part de la seva vestimenta per a ser utilitzada en la càrrega de les peces d'artilleria austriacista; ${ }^{19}$ el de Francisca Paiell, consta - per motius als quals em referiré més endavant- a la crònica de Castellví, en els fets de la matinada del dia $22 ;{ }^{20}$ i aquesta mateixa font fa constar també, a la fi dels combats del matí d'aquest dia, el nom de Francisca Gual, com a exemple d'enteresa davant de les adversitats de la contesa bèl lica, ja que, segons s'explica: «encontró en la bajada de la prisión que llevaban a su hijo malherido. Sin turbarse dijo: «"Ahora luego mandaré otro que me queda y si muere iré yo"». ${ }^{21}$

Algunes de les diferències entre les Proeses... i les altres fonts són força anecdòtiques i, de fet, resulten més útils per comprendre les estratègies literàries seguides en la construcció del text, que no pas per a la seva interpretació. Fixem-nos en dos exemples que, clarament, cal considerar com a meres llicències de què l'autor es val per augmentar l'efecte dramàtic del seu relat. El primer cas el trobem en el passatge comprès entre els versos 19-26, on llegim que l'atac de l'exèrcit francès agafà desprevinguda la defensa de Montjuïc, cosa que no es correspon amb la realitat històrica, atès que es fa difícil de considerar imprevist l'atac francès quan totes les fonts ens diuen que feia quasi vint dies que les tropes borbòniques assetjaven la ciutat i que es batallava pel control de la muntanya

20

24

\author{
Ve lo francès i envesteix \\ (deixem preàmbuls a fora) \\ tan d'improvís a Montjuï, \\ que fou llamp i tro una cosa. \\ Tan desprevingut estava \\ d'un tot, que es perd en una hora \\ a no eixir a la defensa \\ Eulària i santa Madrona.
}

Quelcom de similar passa als versos 75-80, quan se situa les dones desplaçant-se a camp obert durant la batalla. La imatge, sens dubte, pretén subratllar el valor de les heroïnes però l'esment a les «muralles fortes» del castell tampoc es correspon amb la realitat, ja que les cròniques apunten que, en aquelles dates, la fortalesa era poc més que un munt de ruïnes:

19 Mundet, J. / Alsina J.M. (1998: 86 [72r]); Feliu (1999: III, 557).

20 Mundet, J. / Alsina J.M. (1998: 93 [77v]).

21 Mundet, J. / Alsina J.M. (1998: 95 [79r]).

SCRIPTA, Revista internacional de literatura i cultura medieval i moderna, núm. 10/desembre 2017/pp. 191-228 ISSN: 2340 - 4841 doi:10.7203/SCRIPTA.10.11077 


$\begin{array}{ll}\text { 76 } & \text { Dones se veren allí } \\ & \text { de la Ribera, ab pistoles, } \\ & \text { i no dintre del castell, } \\ & \text { tras de les muralles fortes, } \\ & \text { sinó fora, en lo camp pla, } \\ & \text { entre miqueletes flotes, }\end{array}$

On el poema sí que sembla coincidir amb les fonts, encara que només de forma tangencial, és a l'hora d'assenyalar que la col laboració de les dones en la defensa de la ciutat va anar més enllà del dia 22:

$\begin{array}{ll} & \text { tan solament durà } \\ & \text { esta finesa famosa, } \\ & \text { esta gran lliberalitat, } \\ & \text { esta acció tan manirrota, } \\ & \text { est dia de tant perill, } \\ & \text { sinó lo temps que les tropes } \\ & \text { enemigues estigueren } \\ & \text { volent guanyar Barcelona. } \\ & \text { fins que els poguérem cridar, } \\ & \text { de la muntanya: «Mamola!». }\end{array}$

D'acord amb el text, les barcelonines perseveraren en les seves tasques de suport a la defensa del Cap i Casal no únicament durant el dia en què s’intentà la recuperació de Montjuïc, sinó fins al moment en què aquesta es va fer finalment efectiva, $i$ això vol dir, a principis de maig, un cop es va haver superat el setge. Cal dir que, en aquest punt, el nostre text concorda amb el dels cronistes, ja que tant Castellví com Feliu testimonien la continuïtat de la implicació femenina, si bé, a diferència de les Proeses..., especifiquen que a finals d'abril i primers de maig les dones participaren, sobretot, en les tasques de reconstrucció de la bretxa de la muralla. ${ }^{22}$

Ara bé: tot i que el text, bé que més esquemàtic que les cròniques en aquest punt, és ajustat als fets pel que fa a la continuïtat dels esforços femenins després del dia 22, sembla que no ho és tant a l'hora de situar l'inici d'aquests esforços. En aquest sentit, les cròniques ens indiquen que la implicació de les dones no només va començar amb l'inici de l'atac a Barcelona, el dia 3, sinó que es va mantenir al llarg de tot el setge. Sobre el dia 3, per exemple, Feliu afirma que «los nombres de todos los barceloneses, así Hombres como mujeres, bien merecerían quedar escritos con caracteres de bronze en el Templo de la Immortalidad» ${ }^{23}$ i que:

22 Sobre els fets del dia 27 vegeu Castellví (Mundet, J. / Alsina J.M. 1998: 100-101 [93v]) i Feliu (1999: III, 565). Sobre els fets dels primers dies de maig vegeu Castellví (Mundet, J. / Alsina J.M. 1998: 101 [83v]) i Feliu (1999: III, 566).

23 Feliu (1999: III, 556). Aquesta obra, no ha estat, per ara, objecte d'una edició que n’hagi regularitzat les grafies 
Fué prodigioso en esta ocasión el valor de las mujeres y muchachos, pues unos peleando con sus fusiles y los otros mezclados en medio del conflicto con valiente desprecio del riesgo, llevaban refresco a los que peleaban, y municiones, entrándolas en la plaza en medio del conflicto, como los mejores soldados. ${ }^{24}$

Per la seva banda, en referir-se a aquesta mateixa data, las Narraciones... de Castellví reporten que:

\begin{abstract}
Acudieron toda clase de gentes: muchos dejando sus cuerpos, mujeres y niños en gran número, a subir agua y pertrechos; otras subían acomodadas viandas, dándolas de balde a soldados y paisanos; corrían entre los más expuestos riesgos y no pocas con armas. En breve espacio condujeron todos los aprestos necesarios al castillo y al caer la noche en la gran cisterna sólo faltaba palmo y medio de agua. Las mismas mujeres transportaban los heridos, llevaban vendas y paños para curarles y animaban al combate a todos. Sus gritos alentaban a los hombres a despreciar los riesgos. A voces les animaban. Decíanles: gracias a Dios ha llegado el tiempo que decía san Vicente Ferrer que las mujeres llevarían calzones. Estas voces enfurecían al más alto punto el brío de los hombres. ${ }^{25}$
\end{abstract}

Més difícil resulta documentar el paper de les dones entre el dia 3 i el 22, però almenys dues fonts ens donen indicis per pensar que es van mantenir actives, com a mínim col laborant en les tasques d'intendència, al llarg de tots aquells dies. En aquest sentit, l'opuscle Ecos de verdad en siete diálogos sobre lo sucedido en el asedio de Barcelona (Anònim 1707?), explica que, abans del dia 22, les dones pujaven cada matí des de les drassanes cap a la fortalesa per proveir d'aliments i municions als resistents. ${ }^{26}$

(la que cito és una edició facsímil). Tanmateix, per fer el text més proper al lector i per ser coherent amb la resta de textos (tant catalans com castellans) citats aquí, que apareixen, tots ells, en grafies actuals, les cites d'aquesta font es reprodueixen amb les grafies i la puntuació adaptades a la normativa vigent en la llengua castellana.

24 Feliu (1999: III, 557).

25 Mundet, J. / Alsina J.M. (1998: 86-87 [74r]).

26 «Todos los días se hacen abundantes ollas para ellos, se reparten más de cinco mil raciones, que cada una de ellas basta al sustento, contribuyendo a las expensas de ese gasto las comunidades de religiosos, los gremios y otros particulares fijamente con tanto cada semana. A más de eso hay algunas mujeres que hacen sus pucheros y guisados trayéndolos por los cuarteles y siguen sin temor de las bombas y balas todas las avanzadas de los soldados: con que, sin moverse el pie del arma los soldados, lo que sobra para el sustento y lo que basta para el regalo». Ecos de la verdad... (Alabrús 2006: 7-60). Amb tot, no queda del tot clar si en la preparació del menjar per a la tropa hi contribuïen totes les dones o només les de determinats ordes, cosa que sembla suggerir Feliu (1999: III, 559): « (...) muchos particulares contribuían todos los días en el gasto de las ollas, que sobraban para toda la guarnición, pues se distribuían más de cinco mil raciones a más del caldo, y sustento de los enfermos, corriendo el cuidado de los guisados por las Hermanas de la Misericordia, y la superintendencia del gasto por el Doctor Josep Minguella, abogado fiscal patrimonial, por el doctor Anonio Soler, doctor Gabriel Barrera, Francisco Darder, Raimundo Pausa, y otros devotos clérigos y seculares». El més versemblant és pensar que hi devien intervenir tant les dones seglars com les religioses, si bé no és possible de precisar amb més dades com es va organitzar la preparació de la intendència.

SCRIPTA, Revista internacional de literatura i cultura medieval i moderna, núm. 10/desembre 2017/pp. 191-228 ISSN: 2340 - 4841 doi:10.7203/SCRIPTA.10.11077 
Sigui com sigui, i en contrast amb el que apunten les fonts històriques, a les Proeses..., en canvi, no es fa cap menció a la implicació femenina precedent al dia 22, i em sembla que hi ha dos factors que expliquen aquesta circumstància. D'una banda, sense dubte, es tracta d'una estratègia encaminada a revestir d'excepcionalitat -i per tant d'interès- els fets del 22. Però, al mateix temps, potser hi ha també una certa voluntat d'evitar la menció a la situació immediatament prèvia a aquests fets, una situació en la qual, per cert, sembla que les dones tingueren un paper decisiu. Per entendre-la, però, cal que primer ens situem dins el clima polític i social de la Barcelona de l'abril de 1706.

Al llarg d'aquell mes, i davant del risc que suposava haver de suportar un setge en unes condicions tan desiguals, l'estat major de Carles III havia previst l'evacuació de l'Arxiduc per mar cap a Tarragona. $\mathrm{El}$ rumor de la fugida imminent del rei es va escampar per Barcelona i aquesta possibilitat va ser percebuda com el primer pas per a la rendició de la ciutat, un acte que els barcelonins consideraven com una traïció contra ells i de l'estat major contra el monarca, a qui suposaven -o millor dit, atribuïen- la voluntat de quedar-se per defensar la ciutat. L'abandonament de la fortalesa de Montjuïc la matinada del 22 féu sospitar que l'evacuació estava a punt de fer-se efectiva, la qual cosa derivà en un avalot popular de grans magnituds que es dirigí cap a Sant Pere de les Puel les, on residia l'Arxiduc, per exigir al monarca que proporcionés a la gernació els comandaments militars necessaris per liderar una contraofensiva. ${ }^{27}$ L'Arxiduc condescendí a aquesta petició i és en aquest punt -és a dir quan es produí la sortida dels soldats i voluntaris de la ciutat cap a Montjuïc- que ens situa el nostre text. ${ }^{28}$

L'autor, així doncs, no fa cap referència a la situació tumultuosa que precedí el contraatac aliat sobre Montjuïc i en la qual, d'acord amb les cròniques, les dones foren un agent clau. Segons Castellví, elles foren qui advertiren que Montjuïc estava essent abandonat i elles començaren a escampar la idea que calia sortir a defensar la muntanya:

\footnotetext{
Empezóse a retirar los pertrechos del castillejo. Lo advirtieron luego las mujeres que acudieron desde el amanecer a las atarazanas a cargarse de pertrechos para subir a Montjuï, como acostumbraban. Advirtieron que bajaban pertrechos. Empezaron a esparcir la voz que Montjuïc se abandonava. ${ }^{29}$
}

27 Bacallar (1725?: 106) afirma que els exaltats «tumultuaron y sitiaron el Palacio y aun la persona del Rey». Castellví (Mundet, J. / Alsina J.M. 1998: 93 [78r], 97 [80v]) sembla suggerir fins a dues vegades que aquests desordres van ser instigats des de fora, per agents filipistes infiltrats a la ciutat.

28 Sembla evident que l'arxiduc actuà mogut més per les circumstàncies i per evitar mals majors, que no pas per iniciativa pròpia. Els caps finalment designats, segons consta tant a Castellví com a Feliu, foren Jaume Puig de Perafita i el seu fill Francesc i l'alferes Francisco Vila i Lleó. Tot amb tot, les fonts deixen constància del comportament totalment anàrquic del contraatac, amb unes milícies populars incontrolades, que continuaren operant bàsicament al marge de les ordres dels comandaments fins ben avançada la jornada (Mundet, J. / Alsina J.M. 1998: 94 [78v]).

29 Mundet, J. / Alsina J.M. (1998: 93 [78r]). 
A les Proeses... no es fa cap al lusió al rol de les dones com a transmissores d'aquesta informació, perquè de fet el text ens situa directament (som als vv. 57-68) en el moment en què les heroïnes s'afegeixen als combatents que pugen cap a Montjuïc. En aquest punt, llegim:

$\begin{array}{ll} & \text { Pués considerau que fou, } \\ & \text { ab més amor, pressa i còlera, } \\ & \text { lo que en les dones passava } \\ & \text { al sentir: «Montjuïc s'emporten!». } \\ & \text { Deixen cases, pàtria, fills, } \\ & \text { i, com furioses lleones, } \\ & \text { pujant van per la muntanya } \\ & \text { com lo cervo ferit corre. } \\ & \text { Alguns paisans preguntaven: } \\ & \text { «A on, a on anau, dones?». } \\ & \text { «A morir per nostre reil», } \\ & \text { responien ergulloses. } \\ & \text { «A dar ànimo als germans } \\ & \text { que pelean per nostra honra». }\end{array}$

Pot semblar una remarca molt subtil, però penso que hi ha una diferència substancial entre les dones de les Proses..., que, almenys en aquest punt, apareixen com agents que reaccionen «al oir “Montjuïc s'emporten!"» (v. 64) i que responen a la pregunta dels «paisans», i les que, segons Castellví, «Empezaron a esparcir la voz que Montjuïc se abandonava». Perquè no és el mateix sentir una veu que ser aquesta veu. ${ }^{30}$ Més encara: de fet, segons Castellví, podem posar nom i cognoms a una de les barcelonines que encapçalà l'agitació que derivaria en l'intent de reconquesta de Montjuic: «una mujer llamada Francisca Paiell con otras de su séquito empezó muy de mañana a vocear: «"A las armas, a las armas, hermanos, que desamparan a Montjuïc"». ${ }^{31}$

En els moments previs al contraatac aliat, però, són al ludits a les Proeses... de forma força esquemàtica; tant, que, de fet, es resolen en a penes deu versos:

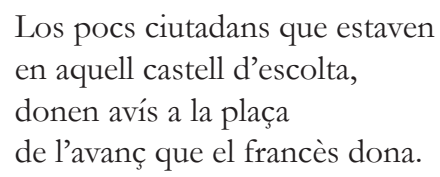

30 Resulta interessant la reflexió d'A. Farge (1992) sobre el paper de les dones en contextos d'aixecaments populars: «En la revuelta, las mujeres funcionan de modo diferente que los hombres, y estos últimos a pesar de saberlo y de consentir en ello, las juzgan. En un primer momento, son ellas quienes se adelantan en la escena, exhortan a aquellos a seguirlas y ocupan las primeras filas del motín. Los hombres arrastrados por los gritos y las incitaciones se suman a la multitud, cuyo volumen contribuyen a aumentar. Saben hasta qué punto impresionan las mujeres que van en primera fila, y saben además que ellas no tienen tanto miedo, puesto que son menos punibles, y que este desorden de las cosas puede ser la prenda del éxito posterior de su movimiento».

31 Mundet, J. / Alsina J.M. (1998: 93 [77v]). 
36

40
I luego (pués só en Montjuïc

saltaré de roca en roca),

de part de sa Majestat

per tot ciutat se pregona,

i de l'Excel lentíssima, que

a Montjuïc tothom còrria.

L'autor no només evita referir-se a la situació tumultuosa, sinó que presenta el contraatac com una iniciativa endegada per les dues autoritats de la ciutat, la reial («sa Majestat») i la municipal («l'Excel lentíssima»). No s'esmenta el paper de les dones com a corretja de transmissió del missatge de Montjuïc a la ciutat.

Si el llegeixo correctament, em sembla que el mateix text ens dona algunes pistes sobre per què l'autor evita referir-se a l'avalot popular de la matinada del dia 22. Les cròniques de Castellví i Feliu afirmen que, abans de sortir de la ciutat, els barcelonins acudiren al Consell de Cent i a la Diputació del General per a què els representats d'aquestes institucions enarboressin els estendards respectius, és a dir, el de santa Eulàlia i del sant Jordi. ${ }^{32}$ A les Proeses..., en canvi, no s'esmenta cap d'aquests estendards, però sí que hi trobem una al lusió a l'ajuda -tan «miraglosa» com inconcretade santa Eulàlia en la defensa de la ciutat. Aquí, però, a diferència de les altres fonts, l'al lusió a la santa no va acompanyada d'una al lusió a sant Jordi, sinó a santa Madrona, copatrona de Barcelona, juntament amb santa Eulàlia (vv. 19-26).

És poc probable que l'omissió del patró de Catalunya i l'aparició conjunta de les dues santes sigui fruit d'una casualitat, sobretot perquè, dins la tradició de la poesia de guerra, santa Eulàlia i santa Madrona solen apareixen juntes quan es tracta d'al ludir a la defensa de Barcelona. ${ }^{33}$ Més encara: tal com ha explicat Farías (2016: 53), Santa Madrona:

(...) o bé esdevé un dels símbols de la ciutat només amb la seva presència, o bé s'erigeix com a protectora de Barcelona a través de la intercessió en les batalles lliurades a la muntanya de Montjuïc, el seu indret de culte per antonomàsia.

En aquest punt, i en consonància amb el que exposa Farías, és pertinent de recordar que, en la mentalitat de l'època, les advocacions tenien un fort component identitari i que els tres sants esmentats no només representaven comunitats polítiques i socials (els habitants de Barcelona, en el cas de les dues santes i els del Principat, en el cas de sant Jordi), sinó també -i, de fet, sobretot- les seves institucions, és a dir, el Consell de Cent i la Diputació del General, respectivament. I, atès que el text no fa cap referència explícita ni implícita a la Diputació, sembla una hipòtesi versemblant

32 Mundet, J. / Alsina J.M. (1998: 93-94 [78r]); Feliu (1999: III, 563).

33 En aquest sentit, a tall d'exemple, dins l'antologia de poesia barroca catalana de Rossich / Valsalobre (2006), trobem dos poemes sobre la batalla de Montjuïc de 1641 en els quals apareixen referències a les dues santes. Són el 77 (Triümfo d'Eulària en Montjü̈), de Josep Català, i 78 (A la rota de Montjuïc, dia de 26 de gener de 1641), anònim. 
pensar que el punt de vista del seu autor deu reproduir el del consistori barceloní. No disposo d'evidències sòlides que vinculin inequívocament l'autor amb el Consell de Cent, però em sembla que, de no ser l'autor algú vinculat d'alguna forma a aquesta institució difícilment hauria deixat d'esmentar sant Jordi perquè costa de creure que no sabés que un dels estendards reclamats per la població de Barcelona va ser el d'aquest sant. I tinguem en compte encara un altre detall: als vv. 35-40, quan es fa referència a la crida a la població perquè acudeixi a la defensa de Montjuïc, les autoritats esmentades són dues: la monarquia i el Consell de Cent (l'Excel tentíssima). Cap referència, doncs, a la Diputació del General:

36

40

\author{
I luego (pués só en Montjuïc \\ saltaré de roca en roca), \\ de part de sa Majestat \\ per tot ciutat se pregona, \\ i de l'Excel lentíssima, que \\ a Montjuïc tothom còrria.
}

Sigui com sigui, que l'autor devia ser algú relativament proper als cercles del poder de Barcelona (si bé no gosaria especificar el grau de proximitat a aquests cercles), es pot inferir del fet que no faci cap al lusió als esdeveniments tumultuosos que precediren les accions bèl liques del matí del dia 22, uns esdeveniments que resultaren certament incòmodes tant per a totes les autoritats de la ciutat.

D'altra banda, i continuant amb la qüestió de l'autoria, cal dir que, malauradament, encara avui s'ha de considerar un aspecte irresolt, i sobre el qual, ja ho avanço, no m'és possible de fer cap aportació substancial. És de justícia remetre'ns a l'estat de la qüestió resumit acuradament per Vall (2015: 154), qui, en relació amb el cèlebre passatge on s'esmenten els noms de Fontanella, Garcia i Miracle (vv. 121-127), explica:

\footnotetext{
Aquest darrer passatge s'ha interpretat com una autoatribució (Brown / Melchor 1995: 39; Baró 2005: 64), per bé que Rossich (2010: 516) ho ha considerat no provat, tot i que admet, com Rubió (1985-1986: III, 15-16; Ruiz 1954: 376), l'al lusió a un escriptor anomenat Miracle, que suggereix que podria tractar-se de Pau, continuador de la Comèdia de santa Bàrbara, de Francesc Vicent Garcia, i abat de Santes Creus -a més, va ser catedràtic de filosofia de la Universitat de Tarragona i va morir el 29 de gener de 1713, havent publicat diversos llibres (Miquel 1961) - o un altre monjo d'aquest convent, Bernardó de segon cognom.
}

L'única cosa que puc afegir a aquestes consideracions és que no s'aprecien coincidències textuals significatives entre les Proeses... i cap de les altres fonts coetànies que reporten l'episodi de la participació de les dones en els fets del dia 22 i que he examinat per al present treball. ${ }^{34}$ Considero per tant improbable que l'autoria de les Proeses... pugui recaure en algun dels autors d'aquestes obres, perquè, de ser així, segurament hagués reproduï -més o menys conscientment- locucions o

34 Aquestes fonts són, a més de Castellví i Feliu, les esmentades a la nota 17. 
passatges de la seva altra obra, ja que aquesta era una pràctica molt habitual a l'època.

També em sembla poc probable que l'autor es trobés a primera línia de foc durant la batalla, però és evident que devia viure-la de prop, perquè demostra conèixer-ne molts detalls. De fet, si ens cenyim al text, fins i tot trobaríem motius per situar-lo prop de l'Arxiduc, perquè, en el darrer passatge, trobem una escena, la del suposat aplaudiment del rei davant l'acció de les dones, que, malgrat que, segurament, faríem bé de no prendre en un sentit literal (no cal pensar que el rei en persona va sortir a aplaudir l'acció, més aviat cal entendre, més simplement, que la va celebrar), també és cert que no és reportada per cap altra font:

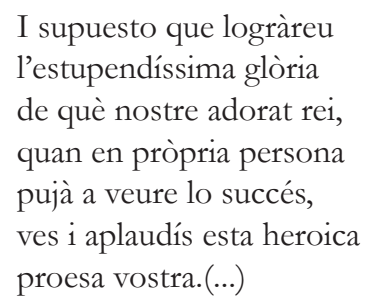

Sigui com sigui, em sembla que hi ha evidències textuals suficients per sostenir, encara que només sigui a mode d'hipòtesi, que l'anònim autor de les Proeses... s'ha de situar dins l'òrbita política del Consell de Cent, així com per descartar que pugui tractar-se d'algun dels altres cronistes dels fets de 1706 considerats en aquest treball. No puc, però, aportar evidències que em permetin anar més enllà d'aquestes dues afirmacions.

\section{L'edició del text}

\subsection{Les edicions setcentistes}

El text ha pervingut als nostres dies a través de set còpies impreses. Quatre d'elles formen part del Fons Bonsoms de la Biblioteca de Catalunya: es tracta dels impresos F.Bon 12727, 569, 5727 i 12724. Els tres testimonis restants es troben a l'Arxiu Històric de la Ciutat de Barcelona (B 1706 $8^{\circ}$ op. 26), al Fons Borja de la biblioteca de la Universitat Ramon Llull (*N 15-II-15a.12) i a la Biblioteca Popular de la Fundació Iluro de Mataró (R. 26601. TOP: 9(46).053).

Cap dels exemplars conservats està datat, però atès que dos d'ells es refereixen al setge com un esdeveniment recent («este setge»), és versemblant pensar que la publicació del text devia tenir lloc poc després de l'acabament del setge, possiblement, durant el mateix 1707. Potser s'hagi de situar en el context de proliferació de publicacions del mes de juny d'aquell any, del la qual deixa constància Castellví, si bé això només pot ser apuntat com a hipòtesi. ${ }^{35}$

35 Mundet, J. / Alsina J.M. (1998: 120 [97r]). Sobre aquesta qüestió vegeu la nota 4. 
Tot i que ho puc provar positivament, penso que hi ha evidències suficients per afirmar que el text va ser objecte de tres edicions. Això és quelcom que no havia estat remarcat fins ara i que demostra que l'obra devia tenir un èxit comercial que, si bé segurament no podem qualificar d'extraordinari -tenim constància de textos de característiques similars amb el mateix nombre d'edicions- sí que devia ser força important.

Els dos primers impresos del Fons Bonsoms i els tres que no pertanyen a aquest fons, formen part d'una mateixa edició, a la qual em referiré amb la sigla A. I siglo B i C, respectivament, els altres dos impresos del Fons Bonsons, el 5727 i el 12724, que, com veurem de seguida, presenten diferències materials i ecdòtiques que els identifiquen com edicions diferents. Cal precisar, també, que entre els exemplars conservats d'A es pot apreciar una única i molt mínima diferència: els impresos Bonsoms difereixen dels altres en la grafia del mot «ja», a l'inici de la segona pàgina (Figura 1), la qual cosa podria indicar que corresponen a emissions diferents de la mateixa edició.

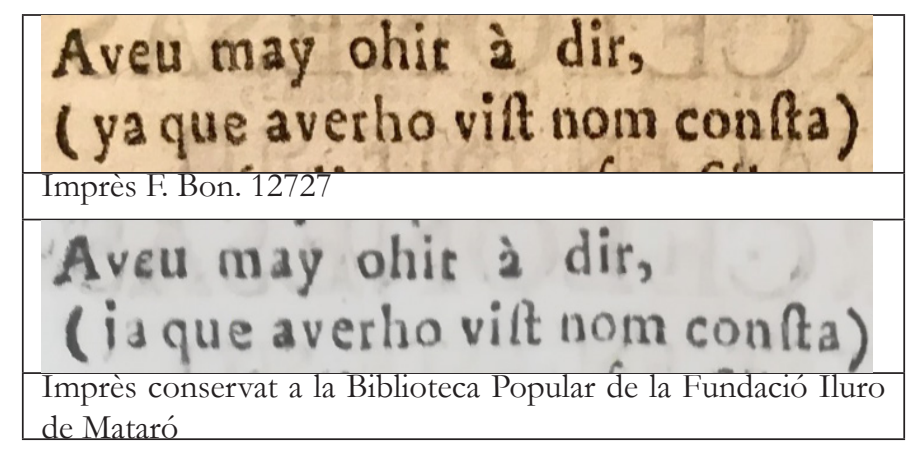

Figura 1.Detall de la diferència de grafies del mot «ja» a la segona pàgina de dos exemplars de les Proeses...

Les evidències en què sostinc la hipòtesi de les tres edicions es troben tant en les característiques materials dels testimonis com en les diferències detectades entre les seves lliçons.

Pel que fa al primer aspecte, cal començar per dir que tots els testimonis tenen una extensió de quatre pàgines $\mathrm{i}$ estan impresos en quart, si bé tenen un llarg de pàgina lleugerament diferent (A: $19 \mathrm{~cm} ;{ }^{36} \mathrm{~B}: 21 \mathrm{~cm}$; C: $20 \mathrm{~cm}$ ). També podem apreciar a primer cop d'ull algunes diferències tipogràfiques notables, la més vistent de les quals es troba en el títol de l'obra, que, a més de contenir una variant (A i C llegeixen este allà on B llegeix lo), presenta una composició tipogràfica diferent en cada un dels testimonis. (Figura 2).

36 Els impresos de l'altra emissió d'A tenen exctament aquest mateix llarg. 


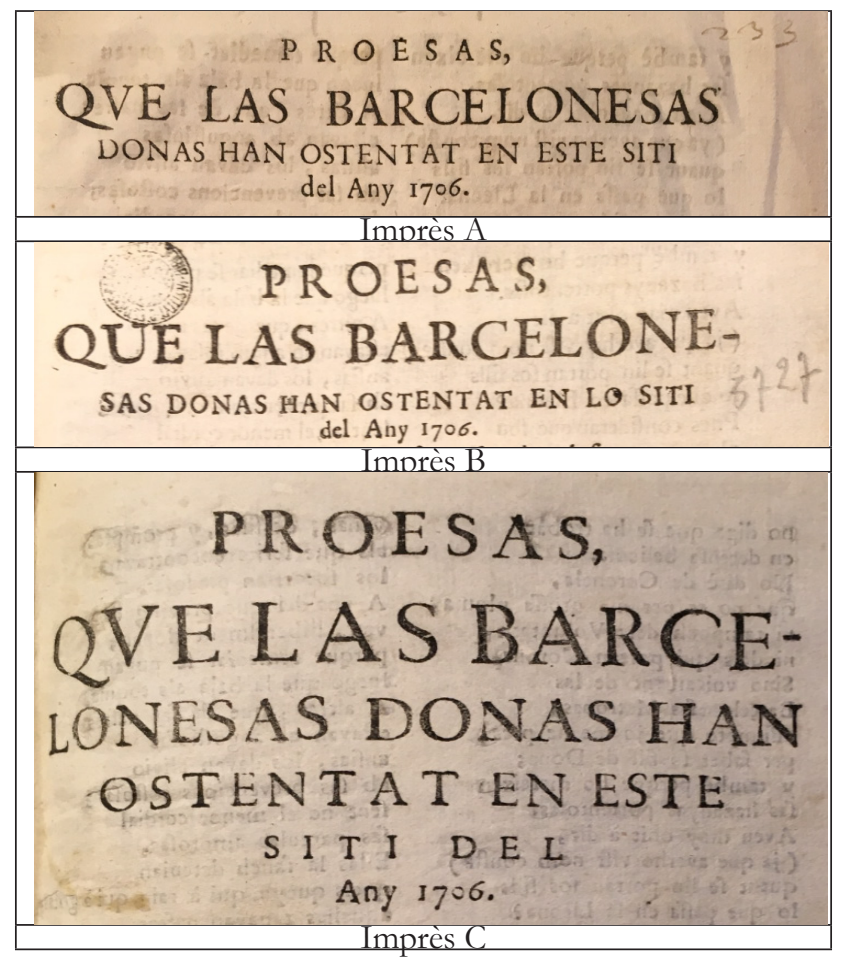

Figura 2. Detall del títol del plec solt en cada un dels exemplars de les tres edicions conservades.

Si ens fixem en el cos del text, observem que $\mathrm{A}$ i $\mathrm{B}$ presenten una composició tipogràfica pràcticament idèntica. De fet, la distribució del text dins les caixes i per les pàgines és exactament la mateixa i les úniques diferències apreciables es troben en el títol, ja que $\mathrm{B}$ utilitza un cos de lletra més gran i segmenta la paraula barcelone-sas, i al final de text, on A indica que el plec es pot adquirir a la botiga de Bartomeu Giralt mentre que B no dóna aquesta informació sinó que, en el seu lloc, hi situa un cul-de-llàntia de motius florals (Figura 3). En canvi, $\mathrm{C}$ presenta una composició de caixes tota diversa de la d'A i $\mathrm{B}$, de manera que la distribució del text en la pàgina no coincideix amb la dels altres dos impresos (Figura 4). 

presenta un peu d'impremta i l'altre un cul-de-llàntia.

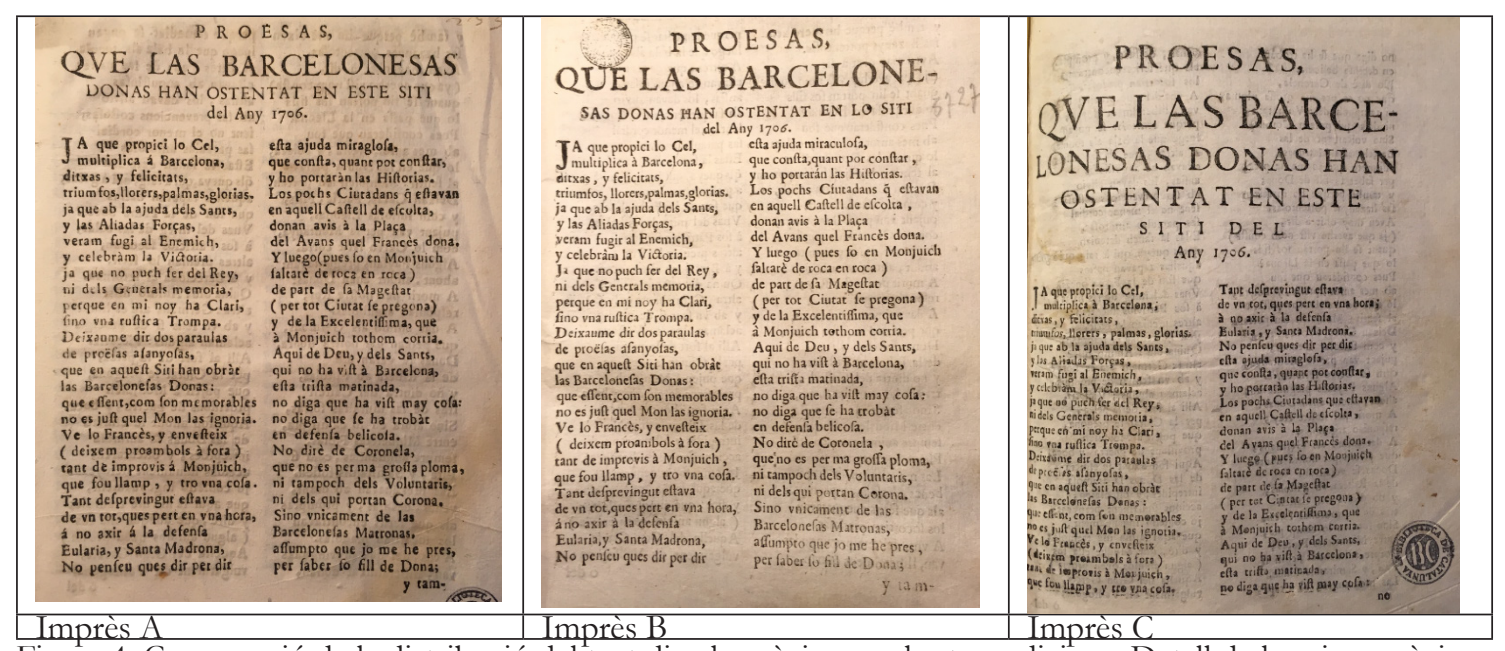

Figura 4. Comparació de la distribució del text dins les pàgines en les tres edicions. Detall de la primer pàgina.

Quant a les lliçons, la comparació revela l'existència de diverses variants textuals. ${ }^{37} \mathrm{~A}$ apareix clarament com el millor dels testimonis disponibles, $\mathrm{i}$ tant aquest testimoni com $\mathrm{C}$ són substancialment millors que B. Per exemple: succeeix fins a tres vegades que la lliçó d'A i C permet satisfer el còmput sil làbic de versos que a B són hipomètrics (vv. 28, 56, 60) i, en un cas, hipermètric (v. 202). És per això que l'edició que presento pren com a testimoni base l'imprès $\mathrm{A}$, del qual únicament esmeno els versos 82 i 103, que contenen errors evidents en tots tres testimonis, i el vers 140, en la qual la lliçó d'A (reproduïda també per B), sembla fer menys sentit que la de C.

Les evidències presentades fins aquí porten a pensar que A devia ser la primera de les edicions i B la segona, i que ambdues devien sortir de la mateixa impremta. C, de la seva banda, sembla posterior a les altres dues o bé he provenir d'una impremta diferent.

Sobre aquesta qüestió, cal recordar que la impressió del plec ha estat tradicionalment atribuïda a Bartomeu Giralt, però aquest és un extrem que, en realitat, no podem afirmar amb seguretat, per dos motius: Giralt només és esmentat al testimoni A i la frase on se l'esmenta (Venense en casa Barthomeu Giralt Estamper, al carrer de / Sant Cayetano) podria al ludir més a la seva condició de llibreter, fefaentment documentada per Camprubí, que no pas a la d'impressor. La referència

37 Sóc del parer que almenys vuit de les variants podrien ser considerades errors tipogràfics sense gaires dubtes. Són les que trobem als v. 55, 56, 118, 130, 131, 182, 184 i 208 (vegeu l'aparat de variants, al final del text editat). Tanmateix, la distinció entre error i variant no sempre pot ser feta amb la mateixa seguretat i és per això que opto per no fer-la en cap cas, i considero com a variants totes les diferències amb implicacions fonètiques detectades en la col lació dels tres impresos. 
prova que Giralt va comercialitzar el plec, però no que en fos l'impressor, encara que aquesta sembli l'opció més versemblant, si més no, per al testimoni $\mathrm{A} .{ }^{38} \mathrm{~B}$ i $\mathrm{C}$ no contenen cap al lusió a l'impressió ni al lloc on es pot adquirir l'imprès i, si fossis sempre els mateixos que $\mathrm{A}$-cosa que no és possible assegurar-, no sabria explicar per quin motiu Giralt hauria estalviat el propi nom en aquestes edicions.

Fet $\mathrm{i}$ fet, no és possible afirmar si totes tres edicions foren obra d'un mateix editor, però sembla versemblant que, com a mínim, A i B ho fossin, més que més perquè, com he explicat supra, presenten una maquetació pràcticament idèntica. Aquesta mateixa línia d'argumentació portaria a pensar que C, en canvi, podria haver sortit d'un altre impressor. Cal insistir, però, que totes aquestes possibilitats només poden ser apuntades a mode d'hipòtesis, per manca d'evidències positives que ens permetin de provar-les certes.

\subsection{Sobre aquesta edició}

Per dur a terme l'edició crítica del text hi havia dues opcions possibles: la primera hauria consistit en acceptar com a provada la hipòtesi esbossada supra, d'acord amb la qual A és la primer edició, i editar aqueta versió del text, prescindint dels altres testimonis, per considerar que la primera acostumava a ser la millor de les edicions.

Ara bé, si bé aquesta hipòtesi és la més versemblant, no puc considerar-la positivament provada, i és per aquest motiu que finalment he optat per realitzar la comparació crítica de tots els testimonis disponibles amb l'objectiu d'escatir, des de les diferències ecdòtiques, les relacions existents entre ells $\mathrm{i}$ arribar per aquesta via a establir quin ha d'ésser utilitzat com a testimoni base. El resultat ha estat el mateix, ja que tot porta a concloure que el testimoni millor per a aquesta funció és l'A. L'única diferència és que l'opció escollida m'obliga a presentar un aparat de variants i un de comentaris a les variants, un aspecte, però, que trobo que tanmateix pot resultar útil al lector que vulgui conèixer els detalls dels diferents testimonis, sense necessitat de tenir-los a l'abast.

La versió de les Proeses... que aquí presento segueix, pel que fa a les grafies, els criteris definits per Rossich (2006) per a l'edició de poesia catalana d'època moderna. Em remeto al text de Rossich per als detalls i indico, només, que, a grans trets, l’aplicació d'aquests criteris implica l'adaptació del text a la normativa ortogràfica actual sense produir-hi canvis fonètics, així com la seva adaptació a la normativa d'apostrofació, accentuació i puntuació vigent.

Cal dir, també, que, atès que, com ja he explicat més amunt, la unitat de sentit semàntic del poema tot sovint no coincideix amb la de la quarteta, com és habitual en els romanços. Per aquest motiu, el sagnat que, en l'edició d'aquest tipus de composició s'acostuma a practicar en el primer vers de

38 «De fet, Bartomeu Giralt va orientar una part de la seva activitat professional cap a l'ofici de llibreter, del qual va fer la mestria l'any 1706, quan ja feia uns quatre anys que tenia impremta oberta. Giralt va ingressar a la confraria dels llibreters de Barcelona el mes de març d'aquell any» (Camprubí 2013: 695). Per més detalls sobre aquest impressor, veg. Camprubí (2013: 694-698). 
la quarteta -precisament, com a indicador visual d'aquest inici- no serviria per a la funció per a la qual està pensat, i és per això que no l’he realitzat.

\section{Conclusions}

\subsection{Resultats}

Amb el present treball he plantejat una aproximació en clau filològica al plec solt intitulat Proeses que les barceloneses dones han ostentat en este siti de l'any 1706. En primer lloc, he situat els fets que l'obra relata dins el context de la Guerra de Successió Espanyola, m’he referit a l'entorn cultural dins el qual apareix, caracteritzat per la presència a Barcelona d'un sector editorial molt desenvolupat i amb una tradició ben consolidada en l'àmbit dels formats efímers i la literatura de guerra en llengua autòctona. He proposat que la publicació de l'obra podria emmarcar-se dins la campanya propagandística que es produí al Principat durant el mes de juny, després que el setge va ser desbaratat i Felip V va haver de passar al Rosselló, tot i que no hi ha cap prova documental que demostri que efectivament fou així. També m’he referit a la implicació de les dones en avalots i conflictes bèl lics en època moderna, que és reportada per les fonts de l'època i resulta relativament habitual, i he explicat que, encara que la lloança de les dones és un topos literari d'arrels antigues, com a tema d'una relació de successos sembla una elecció força singular, darrere de la qual em sembla entreveure propòsits comercials i polítics.

Quant al text pròpiament, he explicat que es tracta d'un poema de bona factura, que s'ajusta a la preceptiva mètrica, fonètica i retòrica, que construeix un discurs ben articulat amb un estil entenedor, sense complicacions lèxiques ni sintàctiques innecessàries, $i$ que està escrit amb un propòsit obertament laudatori. Descriu la implicació de les dones en els combats que tingueren lloc a Montjuïc el dia 22 d'abril i, dins aquest tema, es centra en retratar i celebrar com van proporcionar primers auxilis, avituallament $\mathrm{i}$ ànims als combatents que havien sortit de la ciutat per mirar de recuperar la fortalesa.

La comparació amb obres coetànies de caràcter historiogràfic (principalment, les cròniques de Castellví i Feliu, tot i que no només) ha revelat que el text de les Proeses... no s'allunya substancialment d'aquestes fonts pel que fa a l'explicació dels fets del dia 22, però que omet la implicació de les dones en els combats dels dies precedents, una implicació que l'examen de les fonts permet afirmar que es produí, de forma sostinguda, des del dia 3 fins al 22. Omet també la situació tumultuosa que es produí a l'interior de Barcelona abans del contraatac aliat sobre Montjuic, en la qual, segons les altres fonts, les dones també tingueren un paper important, avisant a la ciutat que la fortalesa estava essent abandonada i incitant la població a sortir a recuperar-la. De fet, a les Proeses... no només s'ometen aquests detalls, sinó que, a més, s'atribueix la iniciativa del contraatac a les autoritats reial i municipal. La constatació d'aquest fet, juntament amb les al lusions a les copatrones de Barcelona, 
santa Eulàlia i santa Madrona, em fa pensar que l'autor del text devia situar-se, de forma més o menys propera, dins l'òrbita política del Consell de Cent. No he pogut, però, aportar noves dades sobre la qüestió de l'autoria, per la qual cosa l'obra s'ha de seguir considerant anònima, amb el benentès que, atenent a l'examen de fonts, puc dir que em sembla improbable que l'autor de les Proeses... fos el mateix que el de les altres obres aquí comentades. En qualsevol cas, l'estudi de les còpies conservades -quatre en total-, ha revelat que el text molt probablement va ser objecte de tres edicions, aspecte fins ara no conegut i que demostra que, en el moment de la seva publicació, l'obra va obtenir un èxit més que notable.

\subsection{Conclusions}

Dit tot això, voldria fer algunes consideracions finals, a mode de postil les. La primera és que n'hi ha prou de llegir el passatge final del text, el de l'aplaudiment de l'arxiduc a l'acció de les dones, per percebre que el text està compost des d'una cosmovisió que, des del punt de vista del gènere és netament patriarcal i, des del punt de vista social, s'adscriu, sense matisos, a l'ordre social de l'antic règim, en el qual el monarca és el cim jeràrquic de l'organització social. Aquesta remarca, no pretén llevar gota d'interès al text ni, menys encara, de restar excepcionalitat al tema que ens presenta, però sí advertir el lector o la lectora que una lectura contemporània en clau de classe o de gènere del text hauria de tenir presents les limitacions que indubtablement presenta en aquests àmbits i que seria irresponsable d'obviar.

Una segona remarca és que l'existència d'una obra com les Proeses... s'ha d'entendre des de la concurrència d'almenys tres factors: el de gènere, el comercials i el propagandístics. El primer, malgrat que és el més vistós, em fa la sensació que és, en el fons, el més epidèrmic i el que menys pesa en la composició del text. Crec -però és una apreciació personal- que el tema proporcionava a l'autor un embolcall per a uns objectius que, comptat i debatut, s'han de relacionar més directament amb els altres dos factors. Quant a l'aspecte comercial, era el reclam perfecte, perquè el tema, com ja he dit, era conegut i apreciat per les classes populars barcelonines, i que aquest reclam devia funcionar ho proven les tres edicions de què el text va ser objecte. Pel que fa a l'aspecte polític, em sembla que el text transmet dues grans idees: en primer lloc, que, en un context de guerra com el que s'estava vivint en el moment de la publicació del plec, l'esment d'un estrat de la societat habitualment no mobilitzat com ho eren les dones no deixa de ser un recordatori a tots els estrats de la població que havien d'estar preparats per ser mobilitzats, si es donava el cas. I aquí entre en joc la qüestió de la llengua: el fet que el poema estigui compost en català respondria, des d'aquest punt de vista, al fet que la població que calia predisposar a la mobilització era, primerament, la del Principat. Vinculada a aquesta idea de mobilització i resistència, i atenent a les al lusions al setge de Tortosa i al del Rosselló que trobem en el text, potser també hem de veure-hi la voluntat de situar Barcelona dins l'imaginari de les ciutats cèlebres per la seva capacitat de resistència, emprant, a més, uns referents que, a diferència dels propis -cal recordar que, des del de 1652, tots els setges 
anteriors als de 1706 havien acabat amb la rendició de la ciutat- resultaven exemplars.

La segona gran idea de tipus polític de què el text ens vol persuadir és que els fets heroics del 22 d'abril de 1706 -uns fets que, no ho oblidem, van permetre guanyar un temps molt valuós que permetria l'arribada de la flota anglesa i el desbaratament del setge- van ser endegats i dirigits per les autoritats reial i municipal, i que el poble de Barcelona, amb les dones al capdavant, va seguir els designis d'aquestes autoritats.

Totes aquestes consideracions ens permeten copsar que un text com el de les Proeses... no és únicament (tot i que també) una font historiogràfica, sinó, sobretot, una obra literària que, com a tal, és polièdrica i susceptible de vehicular continguts i informacions molt diverses. També espero haver reeixit a fer patent que, en la composició d'un text d'aquestes característiques, concorren factors molt diversos, i que al seu darrere no hi ha únicament motivacions polítiques, o comercials o de gènere, sinó més aviat una suma de totes tres coses. Per tot això, amb les evidències i les reflexions aquí presentades, confio haver contribuït a demostrar que, més enllà del seu valor historiogràfic, el text de les Proeses... no només suportava perfectament una aproximació filològica aprofundida, sinó que, de fet, per les seves pròpies característiques, la requeria.

\section{Edició}

\section{Proeses que les barceloneses dones han ostentat en este siti de l’any 1706}

$4 \quad$ triumfos, llorers, palmes, glòries;
ja que, ab l'ajuda dels sants
i les aliades forces,
vérem fugir a l'enemic
i celebram la victòria;
ja que no puc fer del rei
ni dels generals memòria,
perquè en mi no hi ha clarí
sinó una rústica trompa:
deixau-me dir dos paraules
de proeses afanyoses
que en aquest siti han obrat
les barceloneses dones,

Ja que, propici, lo Cel

multiplica a Barcelona

ditxes i felicitats,

triumfos, llorers, palmes, glòries;

a que, ab l'ajuda dels sants

les aliades forces,

vérem fugir a l'enemic

ja que no puc fer del rei

memoria, perquè en mi no hi ha clarí

deixau-me dir dos paraules

de proeses afanyoses

les barceloneses dones, 
que, essent com són memorables, no és just que el món les ignòria.

Ve lo francès i envesteix (deixem preàmbuls a fora) tan d'improvís a Montjuic que fou llamp i tro una cosa; tan desprevingut estava

24 d'un tot, que es perd en una hora a no eixir a la defensa Eulària i santa Madrona. No penseu que és dir per dir

28 esta ajuda miraglosa, que consta quant pot constar i ho portaran les històries. Los pocs ciutadans que estaven

32 en aquell castell d'escolta, donen avís a la plaça de l'avanç que el francès dona. I luego (pués só en Montjuïc 36 saltaré de roca en roca), de part de sa Majestat per tot ciutat se pregona, i de l'Excel lentíssima, que

40 a Montjuic tothom còrria. Aquí de Déu i dels sants: qui no ha vist a Barcelona esta trista matinada

44 no diga que ha vist mai cosa, no diga que s'ha trobat en defensa bel licosa! No diré de Coronela, 48 que no és per ma grossa ploma, ni tampoc dels voluntaris, ni dels qui porten corona, sinó únicament de les

52 barceloneses matrones, assumpto que jo m'he pres per saber só fill de dona i també perquè ho mereixen 56 ses hassanyes portentoses. Haveu mai oït a dir 
Marc Sogues Marco. Proeses que les barceloneses dones han ostentat en este siti de l'any 1706: una aproximació filològica

(ja que haver-ho vist no em consta), quan se li'n porten sos fills,

$60 \quad$ lo que passa en la lleona? Pués considerau que fou, ab més amor, pressa i còlera, lo que en les dones passava

64 al sentir: «Montjuï s'emporten!». Deixen cases, pàtria, fills, i, com furioses lleones, pujant van per la muntanya

68 com lo cervo ferit corre. Alguns paisans preguntaven: «A on, a on anau, dones?». «A morir per nostre reil!», 72 responien ergulloses. «A dar ànimo als germans que peleen per nostra honra». Dones se veren allí

76 de la Ribera, ab pistoles, i no dintre del castell, tras de les muralles fortes, sinó a fora, en lo camp pla,

80 entre miqueletes flotes, sempre animant-les com si Pirra i Semíramis fossen. Les més anaven ab draps, 84 benes, desfiles i, promptes, als que ferits encontraven los socorrien piadoses. A uns, del que previngudes 88 van, lliberalment donen, perquè remediar-se puguen luego que la bala els tòquia. A altres, que de ses nafres

92 estaven ab angustioses ànsies, los daven alívio ab ses prevencions costoses, sent no el menor cordial

96 ses paraules amoroses. Estes la sang detenien, que els queia qui a raig, qui a gotes; 
Marc Sogues Marco. Proeses que les barceloneses dones han ostentat en este siti de l'any 1706: una aproximació filològica

aquelles tapaven nafres

100 que són, de la Fama, boques.

Unes, del mig de les bales, a sos patrícios socorren, altres prenen lo ferit

104 i a Barcelona el retornen. Quina diu: «Ànimo, fills!», altra: «Germans, ara és hora!», i, ab un sens fi de prodigis,

108 aclamen alguns «Victòria!». Allí al fort de la pelea, per la ciutat se pregona que pugen a Montjuic

112 provisions de guerra $\mathrm{i}$ boca. Aquí fou on s'esmerà de les dones l'animosa intrepidès, $i$ ostentaren

116 accions sumament heroïques. Jo confesso ingènuament que aquí la mà me tremola i diré que, aunque ella fos

120 (algun animós que ho pròvia) aquella del gran Garcia (vulgarment dit Vallfogona), o del polit Fontanella,

124 o la que este sigle gosa del Rector de Bellesguard, o la que vui se nos mostra per Miracle, no dubteu

128 que sempre fóra manxola. Perquè, qui podrà explicar, d'un gros exèrcit de dones, (deixant a part lo animós),

$132 \quad$ la diversitat de coses? Qui ab sos braços, qui ab juments, qui ab cistelles, sacs i coves, pujaven la costa amunt

136 ab emulació ditxosa. Pués, de lo que allí obraren ab soldats, paisans i tota manera de defensors, 
Marc Sogues Marco. Proeses que les barceloneses dones han ostentat en este siti de l'any 1706: una aproximació filològica

$140 \quad$ sens témer les borrascoses

ruixades de bales, qui ne busquejarà una còpia?

La gran cisterna que té

144 aquell castell, ab les gotes del suor d'elles s'omplí la major part, si no tota. Quant aquell dia menjaren

$148 \quad$ los milenars de persones que en fortalesa i muntanya estaven com a llagostes, no se degué al fi amor,

152 i forces d'estes matrones?

Pero lo més raro era veure accions generoses ab los més pobres soldats:

156 buscaven-los en les postes i allí los deien: «Germans!, volen de platillo o olla?», i luego de son cistell

160 treien ses lindes cassoles i, voler o no voler, (si bé tothom deia: «Posa!»), los daven del que gustaven

164 no faltant Baco per postres, $\mathrm{ab}$ grossos càntirs de vi acompanyats de pa i coques. I ab plats de peix i de carn,

168 ja fregit i ja en cassola, crussaven los regiments i les catalanes flotes dient: «Qui gusta menjar?

172 Qui vol beure?», i, no ocioses, uns $i$ altres les tenien, i fins capitans d'estofa menjaven allí i bevien,

$176 \quad$ i, així que treien la bossa per a pagar, deien elles: «Vaja, senyor, en bon hora, que no ho fem per interès,

180 sinó per nostra honra pròpia, 
Marc Sogues Marco. Proeses que les barceloneses dones han ostentat en este siti de l'any 1706: una aproximació filològica

per la pàtria i per lo rei, per qui tot ho darem totes». Los inglesos i holandesos,

$184 \quad \mathrm{i}$ altres nacions valeroses que miraven i gustaven de quant portaven les dones, se miraven uns als altres

188 assombrats de tan heroiques accions, i los agraien les fineses a ses modes. No tan solament durà

192 esta finesa famosa, esta gran lliberalitat, esta acció tan manirrota, est dia de tant perill,

196 sinó lo temps que les tropes enemigues estigueren volent guanyar Barcelona, fins que els poguérem cridar, 200 de la muntanya: «Mamola!». Passant per los grans perills de bales, magranes, bombes, experimentant algunes

204 sa operació diabòlica. I encara que elles trobassen a ses companyeres mortes, no per això desmaiaven,

208 antes apar que, embidioses de veure que havien dat més que elles com a lleones, al major perill s'entraven

212 causant embídia no poca al més valerós soldat, al capità de més honra. Oh nobles barceloneses,

216 Oh sempre invictes matrones, eternament duraran hassanyes tan portentoses! Des d'avui parangonau

$220 \quad$ ab les dones de Tortosa i del Rosselló, que foren 


$\begin{array}{ll} & \text { valeroses defensores } \\ & \text { de sa pàtria i sa nació, } \\ 224 & \text { i pasmo de les històries. } \\ & \text { I supuesto que logràreu } \\ & \text { l'estupendíssima glòria } \\ & \text { de què nostre adorat rei, } \\ & \text { quan en pròpria persona } \\ & \text { pujà a veure lo succés, } \\ & \text { ves i aplaudís esta heroica } \\ & \text { proesa vostra. I els demés, } \\ & \text { que no havien vist tal cosa, } \\ & \text { feren tanta admiració, } \\ & \text { que es senyaven moltes voltes. } \\ & \text { I, puix que vostres hassanyes } \\ & \text { rei i los majors blasonen, } \\ & \text { calle ja ma ruda musa } \\ & \text { puix aquell aplauso sobra. }\end{array}$

Romanç heptasil làbic de rima assonant en els versos parells (o/っ_ə).

Aparat de variants

Rúbrica: este A C] lo B | 28 miraglosa A C] miraculosa B | 55 mereixen A B] meteixen C | 56 hassanyes A C] hazanys B | 60 la A C] om. B |79 a fora A B] C fora | 82 Pirra] Pira A B C | 84 benes A B] vanas $\mathrm{C} \mid 103$ prenen] prenien $\mathrm{A} \mathrm{B} \mathrm{C} \mathrm{|} 113$ fou A B] fon C | 118 tremola A C] tromola B | $130 \mathrm{Ce} \mathrm{A} \mathrm{C]} \mathrm{Cn} \mathrm{B} \mathrm{|} 131$ part A B] paat C | 140 temer C] temor A B |162 si A C] sie B | 178 vaja C] baya A B | 182 totes A B] totrs C | 184 valeroses A B] valeosas C | 202 bombas A C] y Bombas B | 206 ses A C] las B | 208 embidioses A C] embidiosa B

\section{Comentaris a les variants}

Baso l'edició en l'imprès $\mathrm{A}$, que esmeno en els versos 82, 103 i 164 per errors manifestos en tots tres testimonis; esmeno també el vers 140, que considero un error de lectura tant en A com en B, i el 178 perquè, si bé la lliçó d'A no és incorrecta, la de C la millora.

$79 \mathrm{El}$ contacte entre vocàlic de sinó a obliga a realitzar una sinèresi per satisfer el còmput vocàlic. 82 Es deu referir al personatge mitològic que avui coneixem pel nom de Pirra (vegeu nota 82 dins l'aparat de notes). He entès que els tres testimonis s'equivoquen, bé sigui per descurança de l'editor $o$ perquè aquest (o aquests) no estaven familiaritzats amb el nom i, un cop produït l'error, ja no podien detectar-lo i, per tant, esmenar-lo.

103 La lliçó dels tres testimonis (prenien) ha de ser un error tipogràfic, ja que no satisfà el còmput sil làbic (causa un vers hipermètric). Per això la corregeixo per prenen, forma verbal que, a més, concorda temporalment amb la dels verbs dels versos anterior i posterior.

105-106 A tots tres testimonis, aquests dos versos són terminats per signes d'interrogació. Els he considerat errors tipogràfics i substituït per signes d'exclamació. 
113 Seguint els criteris de Rossich (2006: 32), canvio la forma ahont, transcrita pels tres testimonis, per on, perquè les dues vocals fan sinèresi.

136 En tots tres impresos, el vers termina amb un signe d'interrogació que he substituït per un d'exclamació, per semblar-me més coherent amb el sentit de la quarteta i pels motius detallats a la nota anterior d'aquest mateix apartat (vv. 105-106).

140 Edito la lliçó de $\mathrm{C}$ perquè és l'única que fa sentit en aquest cas.

164 postres: la lliçó dels tres testimonis (postas) no em sembla que faci sentit, per la qual cosa la considero un error tipogràfic i la corregeixo per postres, que s'adiu més amb el sentit general del passatge.

178 Opto en aquest cas per la lliçó de $C$ perquè és la forma genuïna en català i perquè, de totes formes, no és gens segur que, en aquest cas, la variant ortogràfica respongués a l'existència d'una variant fonètica en la pronúncia de la paraula.

A: afegeix al final del text: «Venense en casa Barthomeu Giralt Estamper, al carrer de / Sant Cayetano».

B: Al final del text, cap afegitó textual, únicament un cul-de-llàntia de motius florals.

C: Al final hi afegeix únicament la paraula FIN.

\section{Notes}

6 les aliades forces: coalició europea conformada pel Sacre Imperi Germànic, la Gran Bretanya, les Províncies Unides, Portugal.

8 celebram: celebrem.

11-12 És una estratègia de captatio benevolentiae per obtenir d'entrada el favor del lector. Amb l'al lusió a la seva rústica trompa l'autor adverteix el lector de la seva suposada manca de perícia literària, amb la qual cosa predisposa el lector a llegir el text amb una major benvolença.

15 siti: setge.

18 ignòria: ignori.

19 lo francès: les tropes de Felip V.

23-26 L'atac va ser tan inesperat que Montjuïc s'hagués perdut en una hora si no arriba a ser perquè santa Eulàlia i santa Madrona, les copatrones de la ciutat, van sortir en la seva defensa.

29-30 La referència és certament críptica, però podria referir-se a aquest fenomen meteorològic recollit per Feliu (1999: III, 557): «durante la pelea aparició en el aire sobre Montjuïc un lucido meteoro que formava la cruz de santa Eulàlia».| les històries: les cròniques històriques.

33 la plaç: Barcelona.

35 pués: en aquest vers $i$ en les següents ocasions que tornem a trobar aquest mot, l'accentuo seguint el raonament de Rossich (2006: 35): «El castellanisme "pues” planteja un problema de mal resoldre: tractant-se d'un monosíl lab pronunciat amb un diftong creixent no normatiu (ja que no va precedit de g o q), resulta que la grafia "pues" només es pot llegir com un mot pla amb accent a la u. És cert que transcriure'l amb un accent a la e ens obliga a llegir-lo com si tingués dues síl labes, però almenys la vocal forta coincideix

amb la que realment es pronuncia, raó per la qual adoptem, com a mal menor, aquesta solució: pués. En poesia, com que només té una síl laba, es pot considerar un cas de sinèresi.

Puntuem segons el costum actual i regularitzem en el mateix». | só en Montjü̈r hi és visualment. No podem afirmar que hi fos realment. De fet, sembla bastant improbable.

37-39 sa Majestat.: l'Arxiduc Carles. | l'Excel lentíssima: la ciutat de Barcelona, i la institució que la 
representa i governa, és a dir, el Consell de Cent.

40 còrria: corri.

41 No he pogut documentar aquesta expressió, però sembla probable que sigui equivalent a l'exclamació «Per Déu i tots els sants».

47 Coronela: cos armat defensiu de la ciutat de Barcelona, integrat per membres dels gremis i comandat pel Conseller en Cap del Consell de Cent.

48 grossa: maldestra, mancada de finor.

50 dels qui porten corona: probablement es refereix al Regiment de les Reials Guàrdies Catalanes, una unitat militar d'elit formada íntegrament per soldats catalans i al servei directe de l'Arxiduc. El seu escut d'armes era el de la Generalitat, que, d'ençà de 1705, incloïa una corona.

52 matrones: dones molt respectables.

54 Literalment, 'Per saber-me fill de dona'.

68 lo cervo ferit. el tema del cérvol ferit prové de Virgili, que l'utilitza per fer referència a la desesperació de Dido (c.f. Eneida IV, 67-74). Adquireix una certa popularitat ja des del segle XIV i el trobem en poetes catalans com Ausiàs Marc i Pere Serafí (Romeu 2001: 97-98; Martín 2007), i així com en la poesia castellana d'aquests segles i del XVII (Lida de Malkiel, 1939), per la qual cosa hem de considerar que, en el moment de la publicació del text, era una imatge àmpliament coneguda.

72 ergulloses: orgulloses.

74 nostra honra: en aquest cas, entre la $a$ de nostra i la $o$ de honra, cal practicar una sinèresi per obtenir el còmput de les set síl labes. | honra: honor.

75-76 Hipèrbaton: 'allí se veren dones de la Ribera ab pistoles'. | La Ribera: barri de Barcelona situat entre Santa Maria del Mar i la línia costanera.

77 el castell: de Montjuïc.

78 tras de les muralles fortes: la consideració és sens dubte exagerada: ja el 15 d'abril Castellví es refereix a la fortalesa com una «informe y derruïda fortificación» (Mundet, J. / Alsina J.M. 1998: 90 [75r]). 80 miqueletes flotes: escamots de Miquelets, les tropes irregulars catalanes del bàndol austriacista.

82 Pirra: malgrat que els tres testimonis grafien 'Pira', molt probablement es refereix a Pirra, personatge llegendari que, segons la mitologia grega, fou la divinitat mare de tot el gènere humà. Semiramis: reina llegendària, considerada una de les fundadores de l'imperi assiri. La cita no sembla del tot afortunada si atenem al fet que, va col laborar a desfer les defenses de la ciutat de Bactra i a prendre la ciutat. Tanmateix, el personatge encarnava l'arquetip de dona guerrera i devia gaudir de certa popularitat a l'època, ja que era la protagonista d'obres teatrals de Virués (La gran Semiramis, c. 1580) i Calderón de la Barca (La bija del aire, 1653), que, versemblantment, podien formar part, encara, de repertori teatral representat a Barcelona en el tombant del segle XVII al XVIII. Sobre el rol d'aquest personatge en totes dues obres, veg. Froldi (2003). | fossen: fossin.

84 desfiles: «Conjunt de trossos de fil provinents d'haver desfilat una tela i destinats a eixugar i netejar ferides, o a servir de vehicle per a aplicar medicines a un queixal, a una nafra, etc.» (DCVB, s.v. desfila). I promptes: ràpides, diligents. (CAL?)

87 previngudes: proveïdes.

88 lliberalment: generosament.

90 luego: immediatament | tòquia: toqui.

95 cordial: «Preparació medicinal que activa l'acció del cor i augmenta la temperatura general del cos» (DCVB).

97-99 estes...aquelles: les paraules i les prevencions.

100 Hipèrbaton: 'que són boques de la Fama'. D’acord amb la tradició clàssica, la Fama és 
representada com una figura femenina amb múltiples ulls i boques, que tot ho sap i que escampa amb gran rapidesa per tot el món tant allò que és cert com allò que és mentida.

102 patrícios: «Persona que per la seva naixença o altes virtuts sobresurt entre els seus conciutadans, i sobretot la que obra en benefici de la comunitat o pàtria a la qual pertany» (DCVB, s.v. patrici). Malgrat que, normativament, el mot ha de ser accentuat, el còmput sil làbic obliga a llegir el diftong final com un hiat.

108 alguns: alguns crits.

111 pugen: pugin.

113-115 Hipèrbaton: 'Aquí fou on s'esmerà l'animosa intrepidès de les dones'.

120 Literalment, 'Qui s'hi vegi amb cor, que ho intenti'.

121-122 Vicent Garcia, rector de Vallfogona (Tortosa?, 1578/1579-Vallfogona de Riucorb, 1623). És considerat l'introductor de l'estètica barroca en la poesia catalana.

123 Francesc Fontanella (Barcelona, 1622- Perpinyà (?), 1682/3), el poeta i dramaturg en llengua catalana més destacat de la segona generació barroca.

124 sigle: segle | la que: la mà que. | gosa: gaudeix.

125 Rector de Bellesguard: nom de ploma de Joan Bonaventura de Gualbes, (Barcelona, 1643 - ?, 1714), poeta en llengua catalana que, a la primeria del XVII, obtingué un cert reconeixement, sobretot, mercès a les seves poesies de caràcter satíric.

126 vii: avui.

127 Probablement es refereix a Pau Miracle, continuador de la Comèdia de santa Bàrbara, de Francesc Vicent Garcia, i abat de Santes Creus o bé a un altre monjo d'aquest convent, Bernardó de segon cognom. (Vall 2015: 154).

128 manxola: manca, però també maldestra. És a dir, que encara que qui reportés aquells fets fossin els grans poetes catalans, ni tan sols el seu tremp poètic (figuradament, la seva mà) valdria per lloar suficientment les proeses de les dones barcelonines.

131 lo animós: els ànims que tenien les dones. | Seguint Rossich (2006: 32), no apostrofo l'article neutre quan, com és el cas, té una funció intensiva. Cal practicar una sinèresi entre entre la $o$ i la $a$ per tal de satisfer el còmput sil làbic.

133 juments: bèsties de càrrega.

142 busquejarà: «Cercar amb insistència» (DCVB, s.v. busquejar).

145 d'elles: de les defensores de Barcelona.

144 aquell castell: el de Montjuïc.

147 Quant: tot allò que.

148 milenars: milers.

156 postes: «Lloc on algú es posa, especialment per a vigilar». (DVCB, s.v. posta).

161 voler o no voler. tant sí com no.

164 D’acord amb la tradició llatina, Bacus és el déu del vi.

170 flotes: escamots. Noti's aquí la diferenciació entre regiments (tropes regulars) i flotes (tropes irregulars).

173 les tenien: rebien les seves atencions.

174 estofa: «Roba, i especialment la de llana o seda». (DVCB). Els capitans que vestien les millors robes, és a dir, els de rang més elevat.

185 gustaven: els soldats no catalans també menjaven les viandes aportades per les dones barcelonines. 189 los: a les dones.

190 a ses modes: a la seva manera (entenent que no podia ésser aquesta la verbal, perquè no parlaven 
Marc Sogues Marco. Proeses que les barceloneses dones han ostentat en este siti de l'any 1706: una aproximació filològica

català).

193 lliberalitat: generositat.

200 de la muntanya: des de Montjuïc. | «Mamola!»: expressió castellana que té l'origen en un gest que consisteix a posar la mà a la sotabarba d'algú, en actitud de burla (veg. DRAE s.v. mamola).

202 magranes: granades d'artilleria.

204 Els efectes de les bales i les explosions, és a dir, les ferides i la mort.

208 antes apar: més aviat semblava.

207 desmaiaven: defallien.

209 havien dat: [la vida] les dones que ara eren mortes.

219 parangonau: sou comparables, teniu parangó.

220-221 les dones de Tortosa i del Rosselló: al lusió a les dones de Tortosa que participaren en la defensa de la ciutat durant el setge musulmà de 1149. La referència a les dones del Rosselló podria al ludir al algun dels setges de Perpinyà $(1473,1572$ o 1642), però no he pogut documentar la participació femenina en cap d'aquests casos.

224 pasmo: admiració. | les històries: les cròniques històriques.

225 supuesto: per descomptat.

235-236 Hipèrbaton: 'i, puix que rei i los majors blasonen vostres hassanyes'. | los Majors: l'estat major del rei. | blasonen: «Celebrar, manifestar els mèrits d'algú» (DCVB, s.v. blasonar).

237 calle: calli.

238 aquell aplauso: l'aplaudiment del rei i del seu estat major. L'aplaudiment no ha d'entendre's, aquí, en un sentit literal, sinó més aviat en un de figurat, com de celebració. | sobra: és superior, guanya. 
Marc Sogues Marco. Proeses que les barceloneses dones han ostentat en este siti de l'any 1706: una aproximació filològica

\section{Bibliografia}

Anònim (1707?) Ecos de la verdad en siete diálogos sobre lo sucedido en el asedio de Barcelona en el año 1706, ms. B.-152, Arxiu Històric de la Ciutat de Barcelona.

Alabrús, R. M. (ed.) (2006) Escrits polítics del segle XVIII. Cròniques de la Guerra de Successió, IV, Eumo, Vic, 5 vol., pp. 7-60.

(2014) «Les dones en els conflictes greus: avalots i guerra», dins Les dones. Barcelona 1700, Barcelona, Ajuntament de Barcelona.

Bacallar y Sanna, V. (1725?) Comentarios de la guerra de España e bistoria de su Rey Phelipe V, Gènova, Matheo Garzizza.

Barcelona atacada pels francesos (2014 [1708-1709?]), Anònim, traducció d'Alejandro Coroleu i Maria Paredes, Barcelona, Adesiara.

Baró i Queralt, X. (2005) La historiografia catalana en el segle del Barroc (1585-1709), tesi doctoral dirigida per Fernando Sánchez Marcos, Universitat de Barcelona [en xarxa]. < http://www. tesisenred.net/handle/10803/2076> [Consulta: 10/09/2017].

Brown, K. / Melchor, V. de (1995) Vida i obra de Joan de Gualbes i Copons, Barcelona, Curial / Publicacions de l'Abadia de Montserrat.

Camprubí, X. (2013) L'impressor Rafael Figueró (1642-1726) i la premsa a la Catalunya del seu temps, I, tesi doctoral dirigida per Agustí Alcoberro, Universitat de Barcelona, 2 vol. [en xarxa]. < http:// www.tdx.cat/handle/10803/129516> [Consulta: 16/08/2017].

(2014) «La circulació de la informació entre Vic i Barcelona durant la Guerra de la Successió», Ausa, 174, pp. 863-889.

(2016) «Butlletes, fulls solts i altres menuderies: la contribució de la impremta al funcionament de la societat catalana moderna», Manuscrits. Revista d'Història Moderna, 34, pp. 113-144.

Coroleu, A. / Paredes, M. (2014) «Introducció», dins Anònim, Barcelona atacada pels francesos, traducció d'Alejandro Coroleu i Maria Paredes, Barcelona, Adesiara.

DCVB, Diccionari català-valencià-balera [en xarxa]. < http://dcvb.iecat.net $>$ [Consulta: 17/11/17].

Ettinghausen, E. (2014) «Celebracions del poder. Política i premsa a Catalunya a començaments de l'edat moderna», Caplletra. Revista internacional de filologia, 57 (tardor 2014), pp. 151-171.

Farge, A. (1992) «La mujer amotinada», dins Duby G. / Perrot, M. (dirs.) Historia de las mujeres en Occidente, Madrid, Taurus, pp. 503-520.

Farías, L. (2016) Imatges de santa Madrona a la Barcelona d'època moderna (segles XVI, XVII i XVIII). Anàlisi de les representacions d'un culte local, Universitat de Barcelona [Treball de fi de grau] [en xarxa]

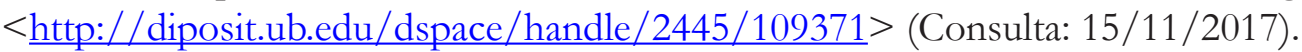


Marc Sogues Marco. Proeses que les barceloneses dones han ostentat en este siti de l'any 1706: una aproximació filològica

Feliu de la Penya, Narcís (1999 [1709]), Anales de Cataluña y epílogo breve de los progressos y famosos hechos de la nacion catalana, III, estudi introductori de Jaume Sobrequés, edició facsímil, Barcelona, Base, 3 vol.

Foguet, F. (2015) «Nòtul les sobre "Comedia famosa del sitio de Barcelona y fuga del duque de Anjou"», de Josep Ribes (1706)» [en xarxa]. < https://ddd.uab.cat/record/130654> [Consulta: 20/09/2017].

Frize, M. (2013) «"Querelle des femmes" and debates on the "woman question"», dins Frize, M. Laura Bassi and Science in 18th Century Europe, Berlín/Heidelberg, Springer, pp. 9-23.

Froldi, R. (2003) «La legendaria reina de Asiria, Semíramis, en Virués y Calderón», Criticón, pp. 315324.

Gabancho, P. (2014) Les dones del 1714, Barcelona, Columna.

Kelly, J. (1982) «Early Feminist Theory and the "Querelle des Femmes", 1400-1789», dins Signs, journal of women in culture and society, vol. 8, 1 (Autumn, 1982), pp. 4-28.

Lida de Malkiel, M. R. (1939) «Transmisión y recreación de temas clásicos grecolatinos en la poesía española», Revista de Filología Hispánica I, pp. 20-63.

Marimon, S. (2013) «Dones en peu de guerra», Diari Ara, 11 de setembre de 2013 [en xarxa] < http:// www.ara.cat/especials/Dones-peu-guerra_0_991100895.html-> [Consulta: 15/09/2017].

Martín, Ll. (2007) «La tradició poètica i moralitzant del cérvol. La poesia 89 de March», dins Estudis de llengua i literatura catalanes LIV. Homenatge a Joseph Gulsoy, Barcelona, Publicacions de l'Abadia de Montserrat.

(2013) «Dones il lustres i dones sàvies, dones amb qualitats masculines?», dins Pomes, J.J. / Redondo, J / Torné R. (eds.) Misoginia, religió i pensament a la literatura del món antic i la seua recepció, Amsterdam, Adolf M. Hakkert Publisher.

Margalef, M.R. (ed.) (2017) Miquel Parets, Crònica. Volum II, I, Barcelona, Barcino, 2 vol.

Massanés, C. / Serra, E (2014) «Les dones del 1714», Säpiens, 138, pp. 56-59.

Miralles, E. (2010) «Poesia i política en la guerra dels Segadors», dins Jané, O. (ed.) Del Tractat dels Pirineus (1659) a l'Europa del segle XXI: un model en construcció / Du Traité des Pyrenées (1659) a l'Europe du XXI siècle: un modèle en construction?, Barcelona, Museu d'Història de Catalunya / Generalitat de Catalunya, pp. 181-191.

(2011) «Propaganda de guerra per a una Catalunya en conflicte: sobre poesia i sobre Gaspar Sala», dins Boadas, S. / García Vicens, D. (eds.) Literatura en la Guerra de Treinta Años, Vigo, Editorial Academia del Hispanismo, pp. 87-108.

(2012) «Els escriptors catalans en una Europa en conflicte: la propaganda política impresa de la guerra dels Segadors», Caplletra. Revista internacional de filologia, 52 (primavera 2012), pp. 181206. 
Marc Sogues Marco. Proeses que les barceloneses dones han ostentat en este siti de l'any 1706: una aproximació filològica

Miquel, F. A. (1961) «Un profesor eximio de Santes Creus en el siglo XVII: Fray Pablo Miracle», Santes Creus, Boletín del Archivo Bibliográfico, II, 13, pp. 121-130.

Mundet i Gifré, J. / Alsina Roca, J. M. (eds.) (1999) Francesc de Castellví, Narraciones históricas, II, Madrid, Fundación Francisco Elías de Tejada / Erasmo Pèrcopo, 4 vol.

Nash, M. (2000) Gènere, identitat urbana i participació ciutadana, Barcelona, Institut de Cultura.

Romeu, J. (ed.) (2001) Pere Serafí, Poesies catalanes, edició crítica, Barcelona, Barcino.

Rossich, A. (2006) «Criteris d'edició (Textos clàssics de l'edat moderna)», dins Rossich, A. / Valsalobre, P. (eds.) Poesia catalana del barroc. Antologia., Bellcaire d'Empordà, Edicions Vitel la, pp. 25-36.

(2010) «La fortuna literària i crítica de Francesc Vicenç Garcia», dins Miralles, E. (ed.) Del Cincents al Setcents: Tres-cents anys de literatura catalana moderna, Bellcaire d'Empordà, Edicions Vitel la.

Rossich, A. / Valsalobre, P. (eds.) (2006) Poesia catalana del barroc. Antologia, Bellcaire d'Empordà, Edicions Vitel la.

Rubió i Balaguer, J. (1985-1986) Història de la literatura catalana, III, Barcelona, Departament de Cultura de la Generalitat de Catalunya / Publicacions de l'Abadia de Montserrat.

Ruiz i Calonja, J. (1954) Història de la literatura catalana, Barcelona, Teide.

Torras i Ribé, J. M. (2007) La Guerra de Successió i els setges de Barcelona, Barcelona, Rafael Dalmau.

Vall i Solaz, F. X. (2015) «La guerra de Successió en el teatre i la poesia catalans de l'època», Manuscrits. Revista d'Història Moderna, 33, pp. 139-174. 